\title{
METALLURGY AND CERAMICS
}

\section{AECD-4046}

U N I T E D

$S T A T E S$

A T $O M I C$

E N ERG Y C O M M I S S I O N

SEMI-ANNUAT, PROGRESS REPORT IN NETALLURGY

For the period October 1, 1950 - March 31, 1951

by

$\mathrm{H}, \mathrm{A}$ 。 Wilhe Im

May 1, 1951

Congolidation of this material into campact forn to permit economical, durecr regroduction hes resulted in multiple folios tor sore pages k.go. 10-12, 27-29, atco

Date Declassified: January 9, 1956

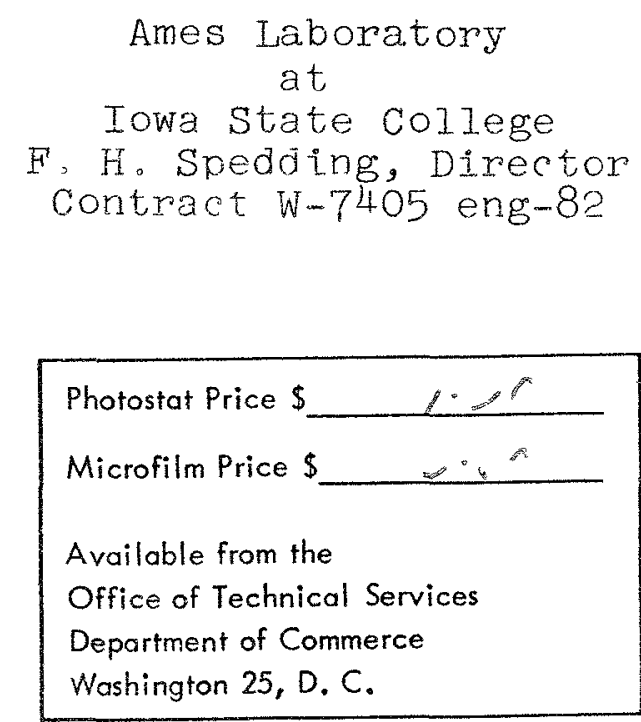

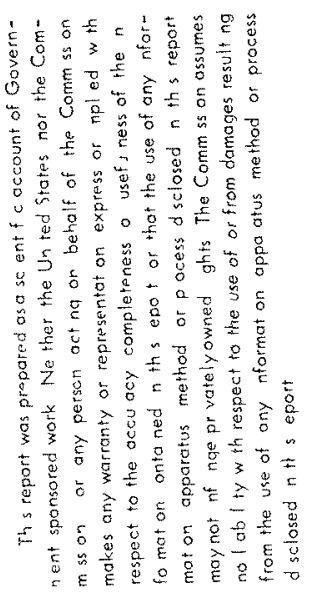

$1-2$

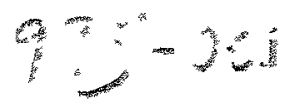





\section{DISCLAIMER}

This report was prepared as an account of work sponsored by an agency of the United States Government. Neither the United States Government nor any agency Thereof, nor any of their employees, makes any warranty, express or implied, or assumes any legal liability or responsibility for the accuracy, completeness, or usefulness of any information, apparatus, product, or process disclosed, or represents that its use would not infringe privately owned rights. Reference herein to any specific commercial product, process, or service by trade name, trademark, manufacturer, or otherwise does not necessarily constitute or imply its endorsement, recommendation, or favoring by the United States Government or any agency thereof. The views and opinions of authors expressed herein do not necessarily state or reflect those of the United States Government or any agency thereof. 


\section{DISCLAIMER}

Portions of this document may be illegible in electronic image products. Images are produced from the best available original document. 
TABLE OF' CONTENTS

Page

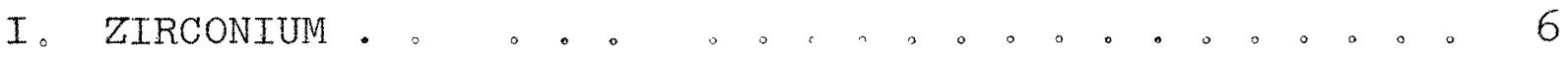

A. Ore Treatment . . . . . . . . . . . 6

B. Zirconyl Chloride Purification 。. 。 。 。 。 7

C. Zirconium-Hafnium Separation 。. . . 。 . . . 7

D. Preparation of Zirconium Tetrafluoride 。.。. 14

E。 Bomb Reductions of Zirconium Tetrafluoride。。。 15

F. Electrodeposition of Zirconium 。...。. 。 。 18

G. Kroll Process Zirconium 。. 。 。 . . 。 。 18

H. Corrosion Testing of Zirconium Alloys 。。。。 20

I. Tin-Zirconium Alloy System 。...。.。。. 23

J. Zirconium-Niobium Alloys, 。 。 。 。 , 。, 31

K. Antimony-Zirconium Alloys 。。。。。。. 。 。 37

I. Zirconium-Carbon System 。. . . . . . 。 。 39

M. Zirconium-Oxygen System ...., 。., 。. . 41

N. Germanium-Zirconium Alioys..., ....., 42

II. THORIUM 。., 。 , , 。, 。 , 。。 44

A. Experimental Bomb Reductions of Thorium Fluoride。 44

C. Welding of Thorium ., ., 。 , . . . . 46

D. Physical Properties of Thorium 。. . . . . . 47

E, Corrosion of Thorium, 。, 。 , , , . . 。 47

$\mathrm{F}$. Thorium Alloys, ..., ........ 48

III. MISCELIANEOUS METALLURGY 。, , 。 . . 。 , 50

A Uranium-Molybdenum Alloys 。. 。。.。. . 50

B. Uranium-Zirconium Alloys 。, 。. 。 。 . . . 50

C. Molybdenum-Rhenium Alloys 。, , 。 . 。 。 51

D. Titanium-Vanadium Alloys, . 。 。 。 。 。, 51

E. Vanadium Reductions o, .........., 55 
Page

IV. EQUIPMENT AND MISCELLANEOUS ITEMS 。. 。。。。 57

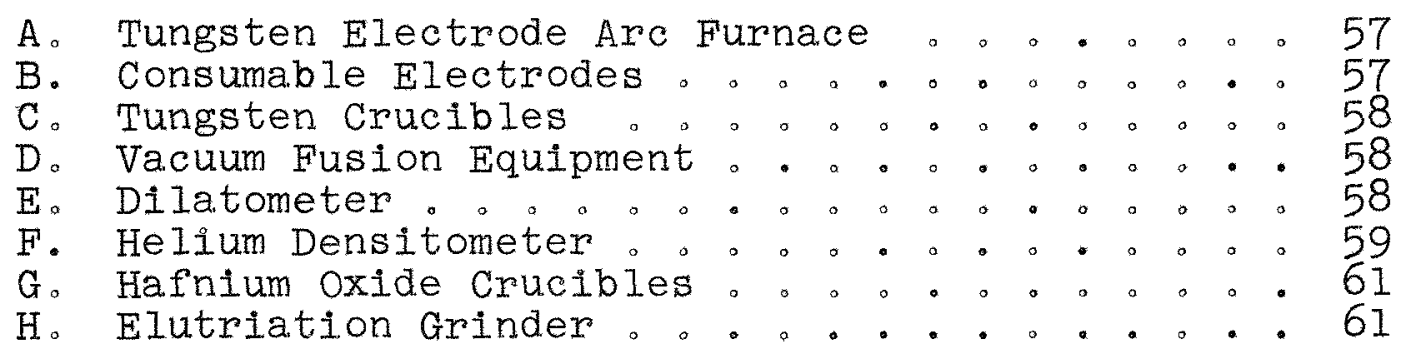




\section{SEMI ANNUAL PROGRESS REPORT IN METALLURGY \\ For the period October 1, 1950 - March 31, 1951}

This report is prepared from material submitted by members of the Metallurgy Groups, Ames Laboratory

Previous semi annual reports in this series are:

$$
\begin{aligned}
& \text { ISC }-6 \\
& \text { ISC }-25 \\
& \text { ISC }-36 \\
& \text { ISC }-45 \\
& \text { ISC }-70 \\
& \text { ISC }-82 \\
& \text { ISC }-128
\end{aligned}
$$




\section{ZIRCONIUM}

Work in the metal lurgy division of the Ames Laboratory involves all phases of zirconium preparation beginning with ore treatment and carrying through to zirconium metal and its alloys. Many of the steps in the series of processes involved are in well developed stages while other portions of the series still need study and development for optimum conditions before setting up the series as a pilot plant.

The processes start with treatment of zircon sand to give a. water solution of the zirconium. Liquid-liquid extraction is being studied as a means for removal of hafnium from the zirconium. The removal of the other impurities in the zirconium obtained. by treatment of the ore are to be removed in the steps before, during and after hafnium removal. The purified zirconium then is to be made into the tetrafluoride which can be reduced by calcium to give metal.

A. Ore Treatment (K.A. WaIsh and J.W. Ross)。

Zirconium tetrachloride can be readily prepared from zircon sand as a starting material and this tetrachloride serves quite well as a source of element for metal production. However, decomposition of zircon sand by fusion with alkali is being studied as a possible alternate process for ore treatment in view of successive processing steps in obtaining zirconium metal. The fusion products can be leached with water, filtered and washed to remove the major portion of the silica as sodium silicate along with other water soluble impurities. Digestion of the water insoluble residue with hydrochloric acid forms a. solution of zirconyl chloride which is filtered to remove the acid insoluble products and unreacted zircon sand.

In one fusion experiment a charge of 325 grams of $\mathrm{NaOH}$ and 250 grams of zircon sand (about $66 \% \mathrm{ZrO}_{2}$ ) was heated to a maximum temperature of $650^{\circ} \mathrm{C}$. The resulting frit was cooled and washed with water. Tests showed the zirconium in the wash to be practically negligible. The residue was treated with $1: 1 \mathrm{HCl}$ and 
heated for 30 minutes. The residue from this acid treatment was less than 3 per cent indicating that about 97 per cent of the zirconium is put in solution by this treatment.

The zirconyl chloride obtained by the above treatment can possibly be purified by recrystallization from hydrochloric acid solution prior to the hafnium separation process. An alternate scheme to be investigated requires treatment of the water insoluble portion of the frit with nitric acid in case it becomes more desirable to use zirconyl nitrate rather than zirconyl chloride for the liquid-Iiquid extraction employed in removal of the hafnium. Elimination of other impurities is to be studied in connection with the a.lka.li fusion process.

In a study of conditions for the alkali fusion treatment of the zircon sand it was found that very little if any reaction occurs at temperatures below $450^{\circ} \mathrm{C}$. Definite and quite complete reaction was found to take place, however, at temperatures of about $550^{\circ} \mathrm{C}$. A pronounced endothermic effect was detected in the charge of $\mathrm{NaOH}$ and zircon sand when heated to a temperature of a.bout $530^{\circ} \mathrm{C}$.

B. Zirconyl Chloride Purification (K.A.Walsh and D。Spink)。

Commercially available zirconium tetrachloride is employed at present to supply material for experimental work in subsequent processes of the zirconium program. The tetrachloride can be put in aqueous solution and crystallized out as a highly purified zirconyl chloride with respect to impurities other than hafnium (ISC-82). This salt can be used directly in the feed solution for the liquid-Iiquid extraction studies and can be readily converted to fluoride for metal reduction studies. The zirconium tetrachloride or this purified zirconyl chloride could serve as a convenient source of zirconium element for subsequent processes worked out at Ames for a metal producing pilot plant.

C. Zirconium-Hafnium Separation (K.A. Walsh and J.Kerrigan)。

Zirconium can be preferentially extracted from hafnium in a. Iiquid-liquid extraction process using tributyl phosphate as the organic solvent. This extraction depends on the distribution of the nitrate to give a satisfactory separation. 
Preliminary experiments were made with aqueous solutions of zirconyl nitrate in nitric acid. Calcium nitrate was added to salt out the zirconium. It was then established that the separation was equivalent with a system containing zirconyl chloride in nitric acid and calcium nitrate. Since the preparation of zirconyl chloride is more convenient, this salt has been employed in subsequent research.

Table I

Dilution of Tributyl Phosphate with Dibutyl Ether

\begin{tabular}{ccccc}
\hline \hline $\begin{array}{l}\text { \% Butyl } \\
\text { Phosphate }\end{array}$ & $\mathrm{K}_{\mathrm{Zr}}$ & $\mathrm{K}_{\mathrm{Hf}}$ & $\beta$ & $\begin{array}{c}\text { \% Hf In } \\
\text { Product }\end{array}$ \\
\hline 20 & 0.84 & 0.043 & 19.6 & 0.21 \\
40 & 2.23 & 0.126 & 17.8 & 0.40 \\
60 & 5.99 & 0.34 & 17.8 & 0.76 \\
80 & 21.1 & 1.14 & 18.6 & 1.35 \\
100 & 50.7 & 3.81 & 13.3 & 1.80 \\
\hline
\end{tabular}

The viscosity of butyl phosphate prolongs the time needed for separation of the immiscible phases. Dilution of the tributyl phosphate with dibutyl ether improved the time factor for this separation. The effect of the addition of butyl ether to tributyl phosphate has been summarized in Table $I$, where $\beta$ represents the separation factor. The initial aqueous solution contained $2.0 \mathrm{M}$ calcium nitrate, $0.5 \mathrm{M}$ zirconyl chloride in which the hafnium content was 2 per cent, and 6 M nitric acid. Equal volumes of the organic and aqueous solutions were employed, although the final volumes showed an Increase in the volume of the organic phase. These results combined with other data suggested that a favorable zirconium distribution and separation can be obtained if the organic phase contains 40 per cent butyl ether.

In an aqueous system in which the only anion is the chloride, very little of the zirconium and hafnium was extracted. The importance of the nitric acid or the nitrate ion was shown by changing the concentration of nitric acid in an aqueous solution containing $0.5 \mathrm{M}$ zirconyl chloride and $2.0 \mathrm{M}$ calcium nitrate. The 
distribution with an equal volume of an organic solution containing 60 per cent tributy 1 phosphate and 40 per cent butyl ether is recorded in Table II. The Increasing value of the distribution coefficient for zirconium with increasing nitric acid concentration suggests that the acid may be partially acting to sa.It out the zircondum.

Table II

Role of Nitric Acid in Separation

\begin{tabular}{lllll}
\hline $\begin{array}{l}\mathrm{M}_{0} \\
\mathrm{HNO}_{3}\end{array}$ & $\mathrm{~K}_{\mathrm{Zr}}$ & $\mathrm{K}_{\mathrm{Hf}}$ & $\beta$ & $\begin{array}{c}\text { \% Hf In } \\
\text { Product }\end{array}$ \\
\hline 3.0 & 0.81 & 0.030 & 26.7 & 0.15 \\
5.0 & 2.92 & 0.089 & 32.8 & 0.28 \\
6.0 & 5.99 & 0.34 & 17.8 & 0.76 \\
7.0 & 6.13 & 0.55 & 11.1 & 1.35 \\
\hline
\end{tabular}

The ability of calcium nitrate to salt out the zirconium from the gqueous phase may be utilized to counter balance the decrease in distribution coefficient accomparying the dilution of tributyl phosphate with butyl ether or a decrease in the nitric acid corcentration. The latter concentration diminishes the solubility of zirconyl chloride wh toh determines the capacity of a column operating on a production basis. This effect of calclum nitrate is shown in Table III, These data were obtained

Table III

Saltirg-out Effect of Calcum Nitrate

\begin{tabular}{|c|c|c|c|c|}
\hline $\mathrm{Ca}\left(\mathrm{NO}_{3}\right)_{2}$ & $\mathrm{~K}_{\mathrm{Zn}}$ & $K_{\mathrm{Hf}}$ & $\beta$ & $\begin{array}{l}\% \text { Hf in } \\
\text { Product }\end{array}$ \\
\hline $\begin{array}{l}1.5 \\
2.0 \\
2.5\end{array}$ & $\begin{array}{r}2.03 \\
5.99 \\
11.08\end{array}$ & $\begin{array}{l}0.11 \\
0.34 \\
0.67\end{array}$ & $\begin{array}{l}18.4 \\
17.8 \\
16.4\end{array}$ & $\begin{array}{l}0.37 \\
0.34 \\
1.1\end{array}$ \\
\hline
\end{tabular}


from an aqueous solution containing $0.5 \mathrm{M}$ zirconyl chloride and 6.0 M nitric acid. Equal volumes of the mixed organic solvent containing $6 \sigma$ per cent tributyl phosphate were employed.

These data were extrapolated to show that a system using $0.5 \mathrm{M}$ zirconyI chloride, 5.0 M nitric acid and I.66 M calcium nitrate should give the desired combination of separation factor, column capacity and purity of product. In later experiments calcium chloride, economically more feasible for the separation, was shown to increase the separation factor to nearly 40 , so this salt was substituted to salt out the zirconium.

The basic design of a multiple stage extractor (Ames Laboratory Internal Report AI-I7) which was used to study the extraction of zirconium with countercurrent flow of the solutions is represented by a sketch of a single stage in Figure 1. The initial position in the cycle of events consists of the extractor being held with the mixer tube $M$ in a horizontal position. From this position the mixer tube which contains both immiscible phases is rocked through an arc of $30-40^{\circ}$ till the two phases become thoroughly mixed or equilibrium is approached. The motion is ceased allowing the separation of the immiscible phases. A clockwise rotation of $90^{\circ}$ drains the upper less dense (organic in this case) layer into reservoir $R_{2}$. An additional $90^{\circ}$ rotation causes the more dense (aqueous in this case) phase to flow into reservoir $R_{1}$. Rotation of $180^{\circ}$ in a counter-clockwise direction them empties the contents of the reservoirs into mixers for the next cycle. A number of these stages side by side and in series are so connected as to cause the contents of the reservoirs to repeatedly flow in countercurrent directions as the above cycle is repeated. operation of such a battery of these stages would result in liquid-Iiquid countercurrent solvent extraction. The feed solution may be introduced at any of the stages, and aqueous scrub solutions and the organic solvent may be introduced at opposite ends.

This basic design includes an adjustable piston $S$ at one end of the mixer tube. In this way the interface position of the phases can be varied to give the apparatus the flexibility to a.ccomodate changes in relative flow rates. An extractor containing twenty stages was constructed for experimental studies. other designs for positioning the interface in the equipment have been set up and tested. The adjustable piston shown in Figure 1 , however, has proven very satisfactory for small scale laboratory separations.

The multi-stage apparatus was used in the extraction of an aqueous feed solution consisting of zirconyl chloride, I.66 M calcium chloride and $2.96 \mathrm{M}$ nitric acid. An aqueous solution 


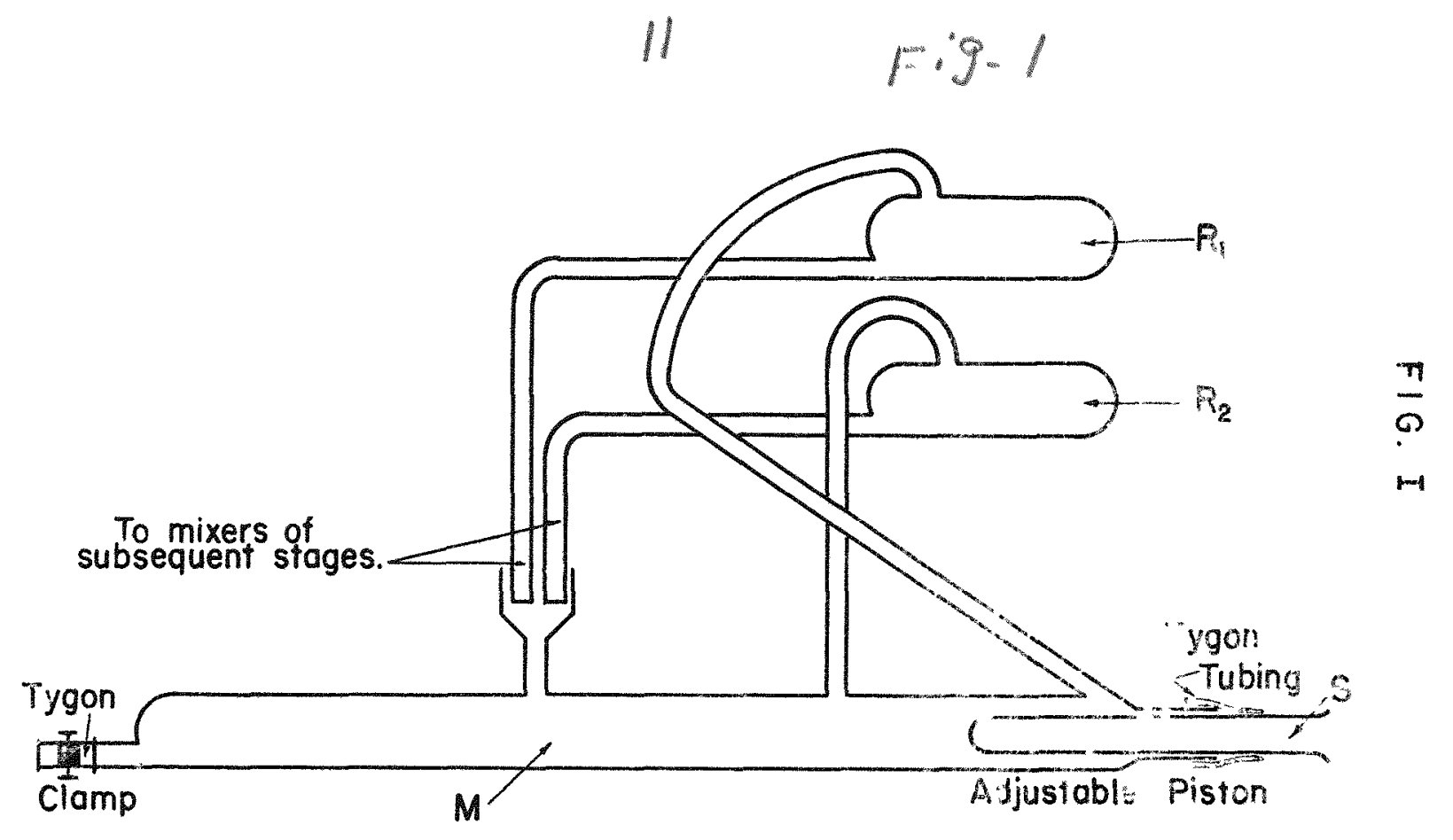


containing $1.66 \mathrm{M}$ calcium chloride and $5 \mathrm{M}$ nitric acid was brought to equilibrium with an equal volume of organic solvent containing 60 per cent tributyl phosphate and 40 per cent butyl ether. The aqueous layer was used for the scrub solution and the organic layer constituted the extraction solvent in the experiment. The results obtained in three experiments using only eleven stages of the extractor are shown in Table IV. It has been shown by a more sensitive analysis that the product zirconium actualiy retained less than 100 p.p.m. hafnium from an original feed containing 2 per cent hafnium. In addition the system showed possibilities for the removal of many of the other metallic impurities associated with zirconium. Further tests of this observation will be made, since it may eliminate the necessity for the purification of zirconium tetrachloride or other zirconium salts used in the preparation of zirconyl chloride. It is evident that this system may be used in the preparation of pure hafnium, as well as for the purification of zirconium.

Table IV

Countercurrent Solvent Extraction of Zirconium

\begin{tabular}{|c|c|c|c|c|c|c|}
\hline$\frac{\text { Volumes }}{\text { Organic }}$ & $\frac{\text { cec }}{\text { Feed }}$ & $\frac{\text { Coycle }}{\text { Scrub }}$ & $\begin{array}{l}\text { ZroCl2 } \mathrm{HfOCl}_{2} \\
\text { in feed (Molarity) }\end{array}$ & $\frac{W t}{\text { Feed }}$ & $\frac{\text { Per Cent }}{\text { Raifinate }}$ & $\frac{\text { Hafnium }}{\text { Product }}$ \\
\hline $\begin{array}{l}25 \\
30 \\
30\end{array}$ & $\begin{array}{l}20 \\
15 \\
15\end{array}$ & $\begin{array}{l}8 \\
8 \\
8\end{array}$ & $\begin{array}{l}0.65 \\
0.65 \\
0.41\end{array}$ & $\begin{array}{r}2.0 \\
2.0 \\
60.0\end{array}$ & $\begin{array}{l}24.8 \\
96.0 \\
99.6\end{array}$ & $\begin{array}{c}0.05 \\
0.05 \\
10.0\end{array}$ \\
\hline
\end{tabular}

Numerous variations were made in the design of the extraction stage. These included modifications so the sequence of events would follow a $360^{\circ}$ cycle instead of the $180^{\circ}$ cycle described above. In this way the apparatus (Figure 2) may be mechanically operated with a timed cycle of events with all rotations in the clockwise direction. An extractor containing twenty of these stages was designed and is being constructed. A large capacity extractor is being designed for pilot plant testing of this type of equipment for large scale production extraction. Designs are being formulated for setting up this type of extractor for automatic and remote controlled operation.

Experimental work has been started on the use of other diluents for use with the tributyl phosphate, since it is believed that 


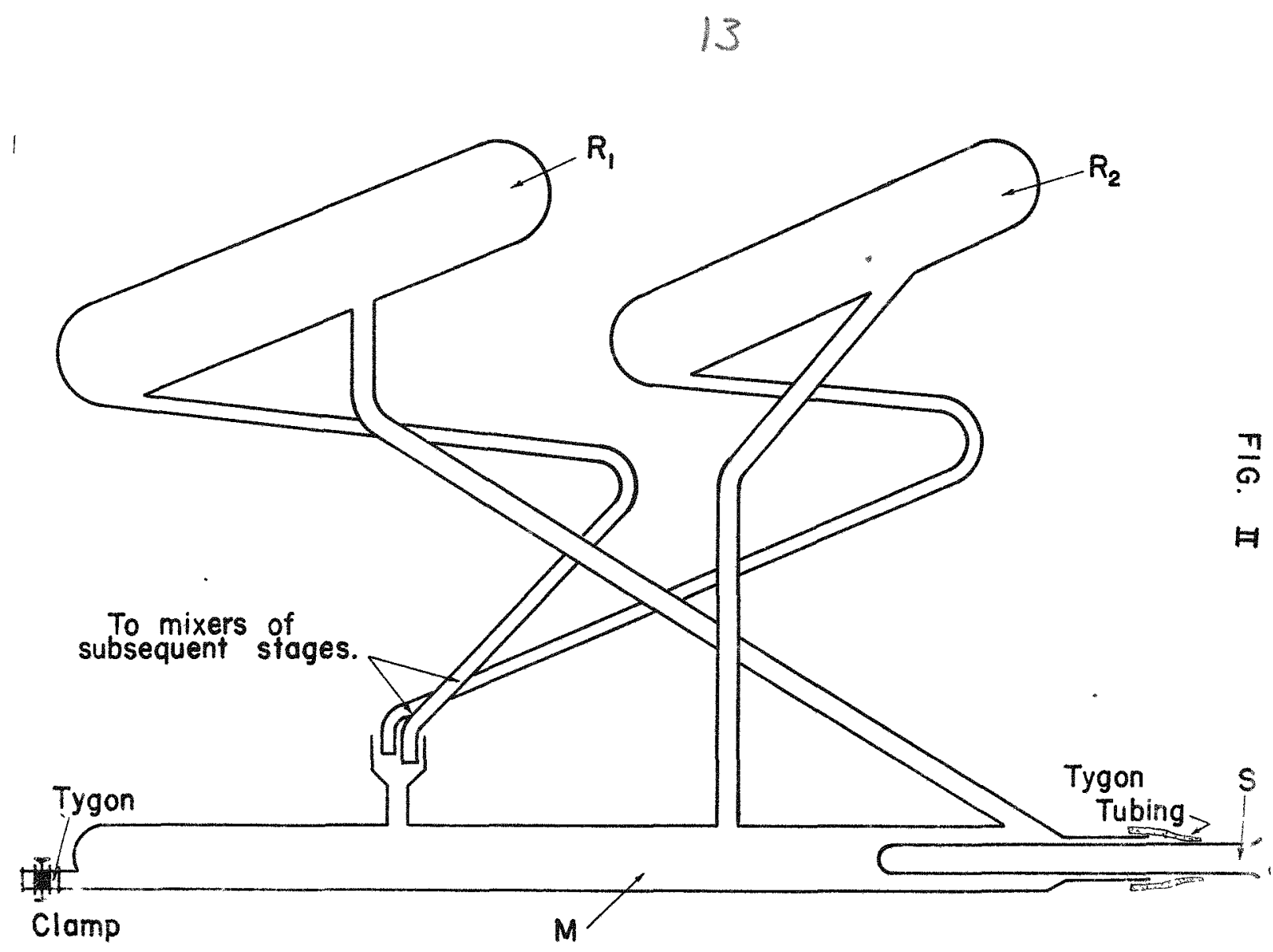


butyl ether may increase the contamination of the zirconium product with trivalent cations. Kerosene, tetrachloroethylene, and hexone have been considered for this purpose.

D. Preparation of Zirconium Tetrafluoride (K.A.Walsh, I. Abate)。

The method of preparation of zirconium tetrafluoride for use in the bomb reduction process has remained essentially the same as that described in detail in previous reports. Briefly, the method consists of adding aqueous hydrofluoric acid to solid zirconyl chloride $\left(\mathrm{ZrOCl}_{2} \cdot 8 \mathrm{H}_{2} \mathrm{O}\right)$ to precipitate $\mathrm{ZrF}_{4}{ }^{\circ} \mathrm{H}_{2} \mathrm{O}$. This wet precipitate is separated from the supernatant solution and air dried until the composition corresponds approximately to that of a tetrafluoride monohydrate. The monohydrate is dehydrated in an anhydrous hydrogen fluoride atmosphere at $300^{\circ} \mathrm{C}$, followed by further treatment at $500^{\circ} \mathrm{C}$.

Using the precipitation and dehydration method outilned above, approximately 340 pounds of zirconium tetrafluoride have been prepared from purified zirconyl chloride. of this amount, 115 pounds were low-hafnium zirconium fluoride ( $<500$ p.p.m.) and 225 pounds were high-hafnium zirconium fluoride (2.0\%)。

The preparation of zirconium tetrafluoride by hydrofluorination of the oxide resulted in poor conversions. In some other methods employed for the fluoride preparation, the product sometimes contains too much oxide to yield a ductile zirconium metal from the reduction process. Separation of zirconium fluoride from less volatile metallic compound impurities, moisture, and non-volatile zirconium compounds was accomplished by a vacuum sublimation of the zirconium tetrafluoride.

Sublimations were made with a stainless steel retort lined with Monel metal. The air-cooled condenser was also lined with Monel metal. Vacuum was obtained with a mechanical pump capable of giving 200-500 microns in the system.

The rate of sublimation was studied as a function of temperature. A time interval of 6 hours was required for complete sublimation of a two kilogram charge, with a furnace temperature of $750^{\circ} \mathrm{C}$. This time was decreased to 2 and $\frac{1}{2}$ hours by raising the furnace temperature to $900^{\circ} \mathrm{C}$. An additional increase to $1100^{\circ} \mathrm{C}$ decreased the time for complete sublimation to 90 minutes.

The purity of the sublimed product is also dependent upon the temperature of the furnace. The partial pressure of impurity 
compounds is increased with temperature, and the quality of the zirconium fluoride sublimed diminished with increasing furnace temperature. A compromise was necessary between the rate of sublimation and the purity of the product. The recommended. operating temperature is $800-850^{\circ} \mathrm{C}$ with a pressure of approximately 300 microns. Under these conditions the sublimed zirconium fluoride yielded ductile zirconium metal. The contamination with metallic impurities in the fluoride was retained at the same low level as that obtained in the zirconyl chloride purification. Analysis of the product gave 12 p.p.m.Fe, 16 p.p.m. N2, 50 p.p.m.

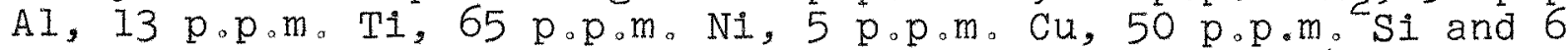
p.p.m. Ca. The fluorine content of the fluoride was 45.2 per cent.

E. Bomb Reductions of Zirconium Tetrafluoride (K.A. Walsh).

Study of the variables involved in the bomb reduction method for the preparation of zirconium metal was continued with special emphasis directed toward decreasing the hardness of the metal. Comparative evaluations of the hardness were made after vacuum melting the reduction product in graphite.

In an attempt to improve the quality of the zirconium metal efforts were made to decrease the nitrogen and oxygen contamination from the atmosphere. For this purpose an evacuation chamber was constructed in which the materials used in the reduction were evacuated and flushed with argon. The chamber containing the material was evacuated to approximately 500 microns. Argon was admitted until atmospheric pressure was equalized. Repetition of this procedure completed the treatment given refractory liner materials and the reduction charges During the addition of the charge to the bomb a stream of argon was admitted through a copper tube lowered into the liner. These operations decreased the amount of air remaining in the bomb as evidenced by the decrease in nitrogen content of the resulting zirconium metal.

A posible source of oxide contamination and thus hardening of the zirconium metal may be attributed to reaction between the molten zirconium-zinc alloy and the oxide refractory liner during the reduction. This possibility was investigated with the use of a graphite crucible in the bottom of a presintered calcium oxide liner. Under these conditions the final hardness of the zirconium was diminished an average of 5 points on the Rockwell "A" scale. 
The quality of the zirconium fluoride was demonstrated to be a factor in the hardness of the metal formed in the reduction. In one experiment ductile zirconium had been obtained, whereas in another case the metal was quite hard. The role of the fluoride was shown when a mixture of the two fluorides gave metal of intermediate hardness. The only difference between these fluorides discernible by available ana.lytical methods was a difference in moisture content. This factor was shown to be unimportant with a. third lot of zirconium fluoride of low moisture content which gave a hard metallic product from the reduction. This fluoride was then given additional treatment with anhydrous hydrogen fluoride at $500^{\circ} \mathrm{C}$. The improvement in the quality of the fluoride was apparent with the resulting decrease in the hardness of the zirconium product as the time of hydrofluorination was increased. From the data obtained it is evident that the quality of the zirconium fluoride is a factor in the hardness of the metal, although there are no analytical methods available to show these differences. However, it is possible to improve the quality of the fluoride by continued hydrofluorination.

Zinc metal is added to the reduction charge to produce an alloy with zirconium which melts at a much lower temperature. This alloying addition greatly improves the recovery of zirconium in the massive form. An increase in the quantity of zinc metal added to the reduction charge gave an important decrease in the hardness of the zirconium metal. The effect of the quantity of zinc included in a reduction charge containing $400 \mathrm{~g}$ 。 ZrF, $64 \mathrm{~g}$ 。 $I_{2}$, and $252 \mathrm{~g}$. Ca can be seen in the summary shown in Table V. From these data it appears that the hardness of the zirconium

Table V

Effect of Zinc on Hardness

\begin{tabular}{|c|c|c|c|}
\hline $\begin{array}{l}\text { g. Zn in } \\
\text { Charge } \\
\end{array}$ & $\begin{array}{l}\text { wt a loss } \\
\text { in casting }\end{array}$ & $\begin{array}{l}\text { Yield of } \\
\mathrm{Zr}, \%\end{array}$ & $\begin{array}{l}\text { Hardness } \\
\text { of cast Zr }\end{array}$ \\
\hline $\begin{array}{r}100 \\
80 \\
60 \\
40\end{array}$ & $\begin{array}{l}51 .-5 \\
50.6 \\
26.4\end{array}$ & $\begin{array}{l}-. \\
89 \\
95 \\
90\end{array}$ & $\begin{array}{l}\text { A50 } \\
\text { A47 } \\
\text { A51 } \\
\text { A64 }\end{array}$ \\
\hline
\end{tabular}


metal is unaffected above a certain minimum addition of zinc to the reduction charge. From the weight loss observed with the casting it is apparent that not a.II of the zinc is alloyed with the zirconium. The variations in yield of zirconium are probably not real, since they fall in the usual range observed in the sma.l scale reduction of zirconium fluoride.

The addition of excess calcium had been instrumental in the past in the formation of zirconium of improved quality. This factor was checked with the use of $80 \mathrm{~g}$. $\mathrm{Zn}$ metal in the charge. In this case the use of only 10 per cent excess calcium gave a. hard zirconium metal. The ductile product was obtained by increasing this quantity to 25 per cent. Further additions of excess calcium were unimportant in improving the quality of the metal above that obtained with the 25 per cent excess.

The quantity of iodine which was employed for thermal effect in the reduction charge was found to have little effect upon the hardness of the zirconium formed. Of greater importance was the effect on the yield of zirconium obtained in the biscuit. Below a certain minimum quantity of iodine the yield of zirconium could not be reproduced. This minimum depended upon the previous history of the filuoride.

For reductions of zirconium fluoride in a $2 \frac{1}{2}$ inch bomb the charge containing $400 \mathrm{~g}, \mathrm{ZrF}_{4}, 80 \mathrm{~g}, \mathrm{Zn}, 64 \mathrm{~g}$. $\mathrm{I}_{2}$ and $252 \mathrm{~g}$. Ca gave the most favorable combination of ductility and purity of the zirconium product. This combination was used in a study of the liner variable, since a jolted liner of a refractory material is preferable in scaling up the reduction process. Under these conditions zirconium metal of high quality was obtained in a jolted liner of calcium oxide. The calcium oxide had been fired at $1600^{\circ} \mathrm{C}$ and pulverized to pass a 60 mesh screen. Electrically fused dolomitic oxide was not a satisfactory refractory since its use increased the hardness of the zirconium. This was further demonstrated by adding quantities of calcium oxide and dolomitic oxide to the reduction charge. Calcium oxide caused no change in the quality of the zirconium metal, while the dolomitic oxide greatly increased the hardness of the product. An addition of zirconium oxide to the reduction charge resulted in an increase in hardness of the zirconium. This Illustrates the detrimental effect of oxygen in the fluoride.

The corrosion rate of zirconium metal formed in the reduction process and cast in graphite is $14 \mathrm{mg} / \mathrm{cm} .2 / \mathrm{mo}$ in $600^{\circ} \mathrm{F}$ water. Grade I crystal bar cast under similar conditions had a corrosion rate of 84. An alloy of zirconium and tin can be 
formed by adding metalic tin to the reduction charge. The resulting alloy of zirconium, zinc and tin was vacuum melted in graphite to eliminate the zinc. A 2 per cent tin alloy prepared. by co-reduction had a corrosion rate of $0.3 \mathrm{mg} / \mathrm{cm} .2 / \mathrm{mo}$. Similar alloys formed by co-fusion of tin and zirconium require an alloying addition of 5 per cent tin to decrease the corrosion rate of graphite-cast zirconium to this value.

\section{F. Electrodeposition of Zirconium (P. Chiotti, R.M. Powers and G. Tra.cy).}

Further work has been done on the electrodeposition of zirconium from fused salt baths. Work has been discontinued on the electrodeposition of zirconium from low melting salt baths since in each case the major part of the deposit consisted of very finely divided metal in a black matrix of unknown composition.

Severa. runs have been made at 800 to $1000^{\circ} \mathrm{C}$ using high current densities and a NaCl-ZrF 4 bath. Coarse black sponge-like deposits were obtained from which fairly coarse particles of zirconium metal were separated by crushing the deposit and washing with water. Approximately $60 \%$ of the metal recovered consisted. of a very fine black powder which could not be washed free of impurities. Much of the impurity is believed to be due to hydrolysis of zirconium salts during washing.

Electrolysis of a $\mathrm{NaCl}-\mathrm{K}_{2} \mathrm{ZrF} 6$ bath at about $800^{\circ} \mathrm{C}$ in the equipment shown in Figure 3 also gave a sponge-like deposit. Cathodes of metal, water cooled, and of graphite have been used. in the electrolysis. Considerable reaction usually occurred on the graphite cathode giving very poor quality zirconium, while the deposits on water cooled metal was much improved (see Figure 4).

G。 Kroll Process Zirconium (B.A. Rogers and W.N. Miner)。

Further work on making zirconium by the Kroll process of reducing $\mathrm{ZrCl} 4$ with magnesium has resulted in the production of a. small amount of zirconium. An ingot of this metal made in the tungsten arc furnace had a hardness of Rockwell A 50 and could be reduced 90 per cent in thickness by cold-rolling. The best results were obtained when a maximum charge of 1250 grams of $\mathrm{ZrCl}_{4}$ was allowed to react with 342 grams of ma.gnesium to 


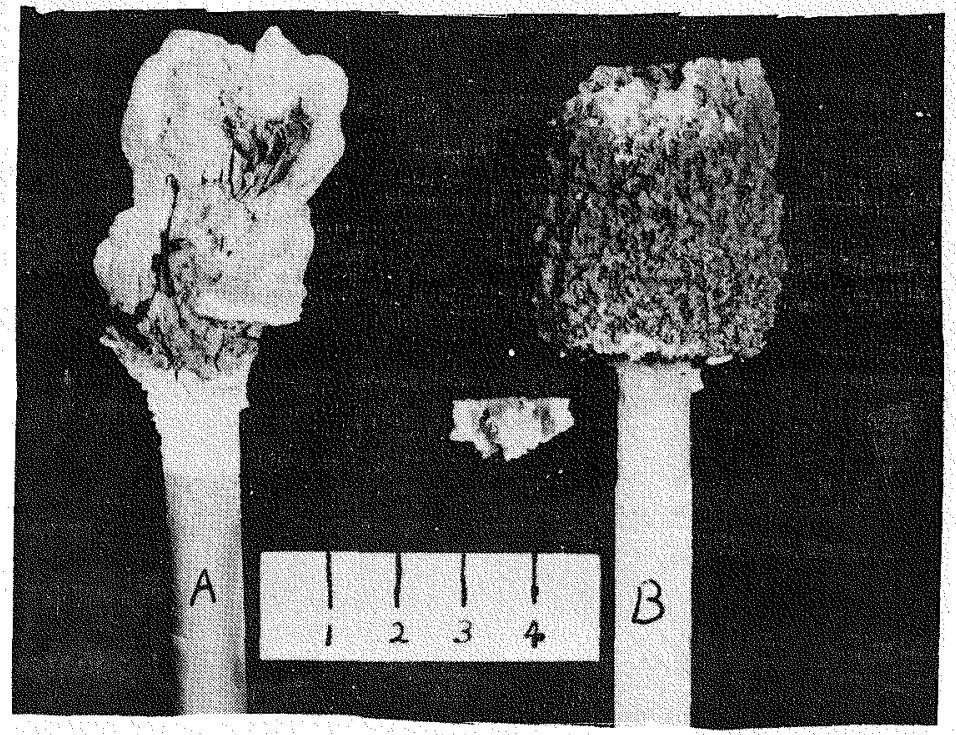

Fig. 3. Electrolytic $\mathrm{Zr}$ Deposits

Zr powder deposited on both one inch graphite (A), and on water cooled nickel (B) cathodes. Wide spread interaction with the graphite is evident. A fragment chipped from the deposit on the nickel cathode shows the relative amounts of $\mathrm{Zr}$ powder (dark) and salt (white) at the outer portions of the deposit.

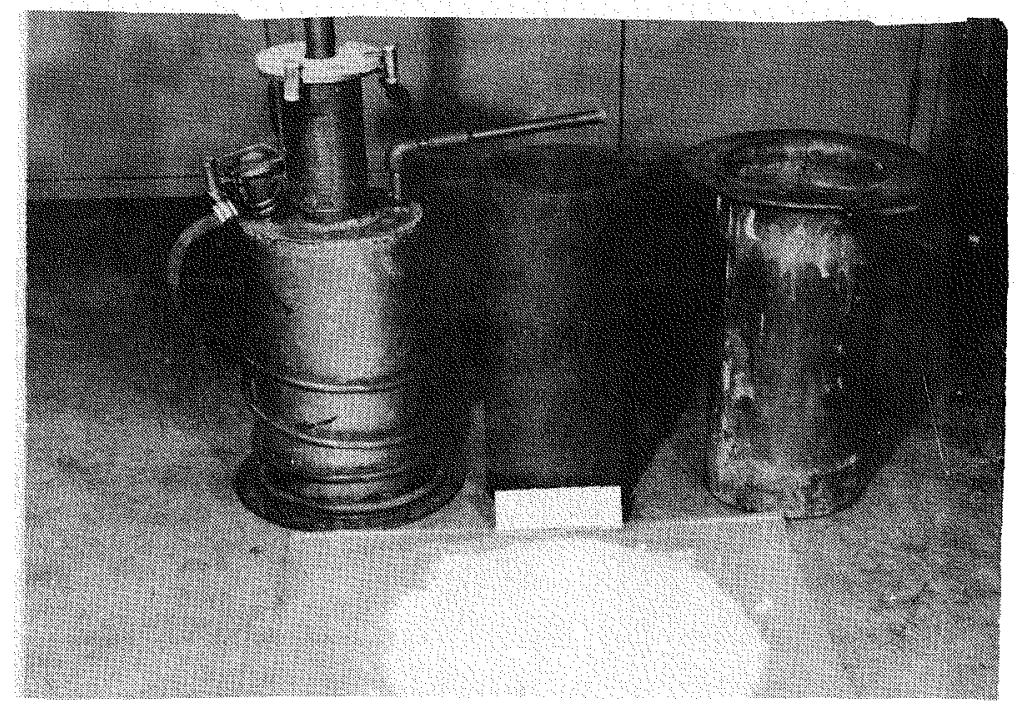

Fig. 4. Electrolysis Crucible and Container

From right to Ieft are shown a nickel crucible holder with its anode connection. $5^{\prime \prime}$ I.D. graphite crucible for holding the fused salt, and a need for withdrawal and cooling of the cathode deposit under argon. The 3500 gram salt mixture used as the - lectrolyte is shown in the foreground. A resistance pot furnace is used to heat the charge for electrolys is. 
give 200 grams of recoverable zirconium. Smaller charges of $\mathrm{ZrCl}_{4}$ gave zirconium with much higher hardness, usually from Rockwell $A$ 60 to A 70. This harder metal was also considerably less ductile. It was further noted that softer metal was obtained if the sponge zirconium was arc melted immediately following the purification step of removing magnesium and its salts. Sponge that had been allowed to stand in the laboratory for several days before being melted gave metal with a hardness of Rockwell A 60 as compared with A 50 when melted immediately. New equipment under construction will permit the operation to be scaled up to about 500 grams of zirconium per run.

H. Corrosion Testing of Zirconium Alloys (B.A. Rogers, and J.T. Williams)。

The corrosion testing of zirconium-base alloys has been continued on a routine basis. The procedure remains essentially the same as that reported in ISC-128. A number of binary zirconium alloys containing small percentages of cerium, copper, lanthanum, neodymium and praseodymium were tested and found to have very poor corrosion resistance. On the other hand, tests on zirconium-antimony alloys have shown indications of good corrosion resistance.

Recent work with some of the zirconium-tin alloys seems to show that for each tin content there is a definite amount of carbon that can be tolerated without destroying the resistance to corrosion. This maximum amount probably is of the magnitude of a few thousand $p \circ p . m$. but the data are still insufficient to establish definite limits. Zirconium-tin alloys melted in a. graphite crucible in a resistance furnace have consistently shown considerably greater corrosion resistance, than similar alloys melted in graphite in a high frequency induction furnace. Both sets of a.lloys were made from zirconium produced in the Ames Laboratory. The tests extended over a period of 472 hours. The difference in corrosion resistance may be due to the lack of stirring action in the melt in the resistance furnace and the consequent minimizing of carbon contamination from the graphite mold.

Table VI summarizes the recent corrosion information for zirconium alloys cast in graphite while Table VII summarizes the data for arc-melted zirconium alloys. 
Table VI

Corrosion of Zirconium Alloys Cast in Graphite

\begin{tabular}{|c|c|c|c|}
\hline $\begin{array}{l}\text { Alloying } \\
\text { addition } \\
\text { wt. \% }\end{array}$ & Method of Preparation & $\begin{array}{c}\text { Corrosion } \\
\text { rate } \\
\mathrm{mg} / \mathrm{cm}^{2} / \mathrm{mo}\end{array}$ & $\begin{array}{c}\text { Duration } \\
\text { of test } \\
\text { hrs. }\end{array}$ \\
\hline
\end{tabular}

$2 \mathrm{Ce}$

$2 \mathrm{Ce}$

$0.76 \mathrm{Cu}$

$3.25 \mathrm{Cu}$

2 La.

$2 \mathrm{Nd}$

$2 \mathrm{Nd}$

$2 \mathrm{Pr}$

$5 \mathrm{Sn}, 1 \mathrm{~Pb}$

O $\mathrm{Sn}$

$0.5 \mathrm{Sn}$

$1 \mathrm{Sn}$

$2 \mathrm{Sn}$

O Sn

O Sn

$2 \mathrm{sn}$

$3 \mathrm{sn}$

$4 \mathrm{Sn}$

$5 \mathrm{Sn}$

$5 \mathrm{Sn}$

O Sn

O Sn

$2 \mathrm{Sn}$

$3 \mathrm{Sn}$

$4 \mathrm{Sn}$

$5 \mathrm{Sn}$

$5 \mathrm{Sn}$

O Sn

$2 \mathrm{Sn}$

3 Sn

$4 \mathrm{Sn}$

$5 \mathrm{Sn}$

$0.5 \mathrm{Sb}$

$1 \mathrm{Sb}$

$5 \mathrm{Sb}$
Bomb reduction

Co-melted with Ames zirconium

Bomb reduction

Bomb reduction

Co-melted with Ames zirconium

Bomb reduction

Co-melted with Ames zirconium

Bomb reduction

co-melted with crystal bar zirconium

Bomb reduction, resistance melted

Bomb reduction, resistance melted

Bomb reduction, resistance melted

Bomb reduction, resistance melted

Crystal bar zirconium, induction melted

Crystal bar zirconium, resistance melted

Co-melted with crystal bar zirconium, induction melted

co-melted with crystal bar zirconium, induction melted

Co-melted with crystal bar zirconium, induction melted

Co-melted with crystal bar zirconium, lnduction melted

Comelted with crystal bar zirconium, resistance melted

Bureau of Mines zirconium, induction melted.

Bureau of Mines zirconium, resistance melted

Co-melted with Bureau of Mines zirconium, induction melted

Co-melted with Bureau of Mines zirconium, induction melted

Co-melted with Bureau of Mines zirconium, induction melted

Co-melted with Bureau of Mines zirconium, induction melted

Comelted with Bureau of Mines zirconium, resistance melted

Ames zirconium, induction melted.

Co-melted with Ames zirconium, induction melted

Co-melted with Ames zirconium, induction melted

co-melted with Ames zirconium, induction melted

Comelted with Ames zirconium, induction melted

Bomb reduction

Bomb reduction

Bomb reduction

Bomb reduction complete oxidation

complete oxidation

26

complete oxidation

106

56

88

complete oxidation

$\begin{array}{rr}510 & 88 \\ 0.5 & 837\end{array}$

$14^{\circ} \quad 318$

$6 \quad 318$

$2 \quad 318$

$0.4 \quad 318$

$97 \quad 318$

$9 \quad 239$

$1.2 \quad 318$

$1 \quad 318$

$0.3 \quad 318$

$0.4 \quad 318$

$0.2 \quad 976$

$100 \quad 318$

$6 \quad 130$

$13 \quad 318$

$11 \quad 318$

$5 \quad 318$

$17 \quad 318$

$0.2 \quad 867$

16

20

15

10

lost wt

0.1

5

lost wt 
Table VII

Corrosion of Arc Melted Zirconium Alloys

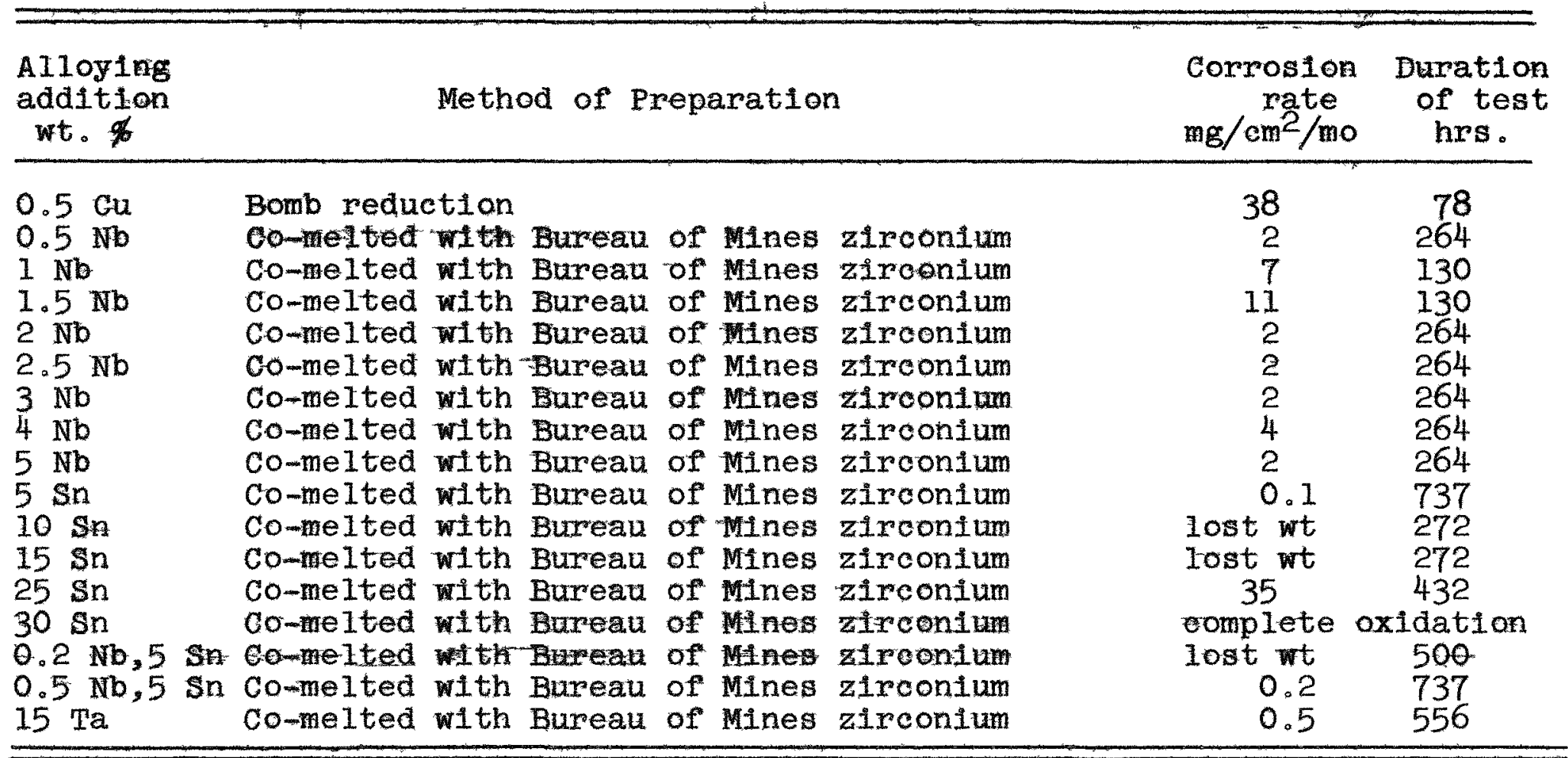


No significant differences have yet been found between the corrosion rates obtained in crevice corrosion tests and those obtained in the standard tests on similar material. However, the crevice corrosion tests should be more fully investigated before conclusions are drawn.

The bombs used in corrosion testing have been modified with a view toward making them safe for tests at $400^{\circ} \mathrm{C}$. The minimum effective wall thickness has been increased from about $1 / 4$ inch to about $1 / 2$ inch thus roughly doubling the strength of the bomb. It is expected that corrosion tests at higher temperatures will show up poor metal much faster and will accelerate the tests so that the amount of information made available over a period of time will be considerably increased.

I. Tin-Zirconium Alloy System (O.N.Carlson, J.M. Dickinson, P。 Armstrong and D.J. Kenney).

A study of the tin-zirconium binary system has been made as part of the program being carried out on the above a.1loy. This has been investigated extensively and an equilibrium diagram proposed on the basis of existing data. The results will be summarized in a paper to be presented at the Materials and Metallurgy information meeting at Oak Ridge in April.

The phase diagram has now been revised somewhat from the tentative one postulated in the previous semi-annual report and now appears in the modified form shown in Figure 5. There is still some uncertainty as to the exact limits of solid solubility in alpha zirconium, otherwise that portion of the system is believed to be weII confirmed. The tin-rich end of the system has also been studied quite extensively although the exact composition of a compound Iying at around $72 \%$ tin has not been established conclusively. The possibility of a compound associated. with the peritectoid for zirconium rich alloys has been considered but investigations to date have revealed no supporting evidence.

Alloys were prepared from crystal bar zirconium and pure bar tin in graphite crucibles and melted in an induction furnace. From 0.15 to $0.2 \%$ carbon is introduced by the graphite crucible but this amount does not noticeably affect the alpha-beta transition temperature in zirconium and propably has only very minor effects on liquidus and solidus positions. Arc melting and resistance furnace heating were a.lso tried in alloy preparation but a strong tendency toward segregation was frequently observed in 


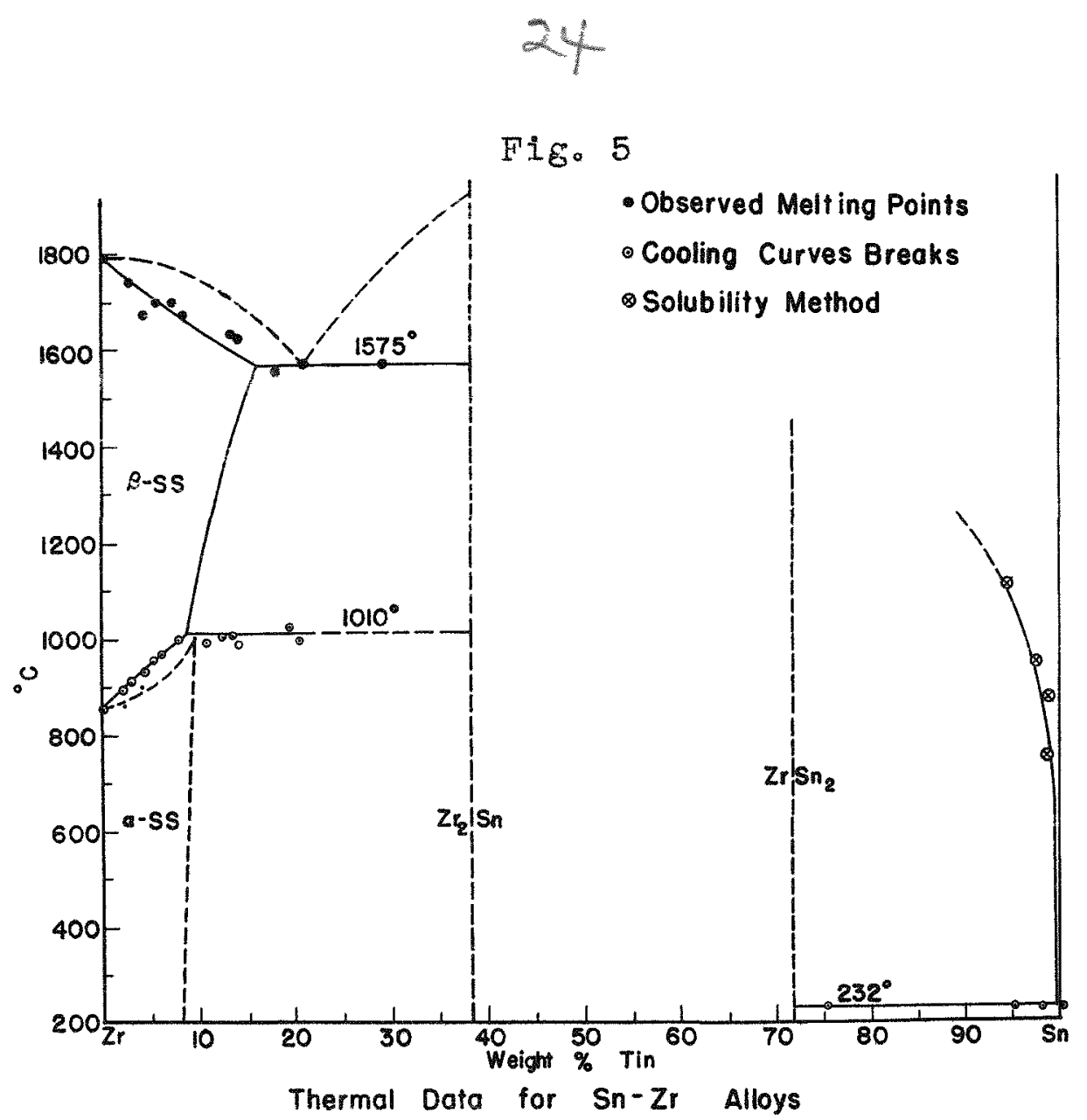


such alloys. The zirconium solidus curve was determined by employing the method of Pirani and Alterthum on bars of various a.loy compositions. The solidus temperatures were taken as the temperature at which liquid was first observed upon heating.

The alpha-beta transition points were determined from cooling curves in which a differential thermocouple technique was employed measuring the temperature difference between the a.110y and a reference specimen or so called "neutral body". Temperature versus differential temperature were plotted on a Leeds and Northrup $\mathrm{X}-\mathrm{Y}$ recorder.

The tin-rich liquidus points were obtained from the chemical analysis of the liquid which was formed by maintaining molten tin in contact with an excess of pure zirconium at various temperatures, $750^{\circ}, 850^{\circ}, 950^{\circ}$ and $1100^{\circ} \mathrm{C}$ for about one-half hour. Longer annealing periods tended only toward the formation of more solid compound while the tin rich liquid phase decreased but maintained constant composition.

The melting point of the assumed compound, $\mathrm{Zr}_{2} \mathrm{Sn}$ was approximated from casting data. The alloy corresponding to ZrSng, however, seems to decompose rather vigorous $1 \mathrm{y}$ at about $1500^{\circ} \mathrm{C}$ when heated in a vacuum.

The location of the eutectic at about $21 \% \mathrm{Sn}$ is based on microscopic evidence (Figure 7) as is the location of the compound at about $40 \%$ sn which corresponds most closely to the composition Zrosn. The microstructure of a $30 \%$ sn alloy (Figure 8) reveals the presence of a primary compound phase plus eutectic. From Xray powder data on annealed samples of 14, 21 and $30 \% \mathrm{Sn}$ alloys the two phases present were ldentified as alpha solid solution and the assumed $\mathrm{Zr}_{2} \mathrm{Sn}$.

The limits of solid solubility were assigned from the microstructures of quenched alloys. The results of a series of quenches are represented in Figure 6 . The $800^{\circ}, 970^{\circ}, 1050^{\circ}$ and $1135^{\circ} \mathrm{C}$ series were annealed for periods of 24 hours prior to quenching in water. In quenching from the higher temperatures, the alloys were annealed for about one hour at temperature in an induction furnace and then quenched in molten wood's metal, the entire operation being carried out under vacuum.

The solid solubility of tin in beta zirconium was found to increase sharply with increasing temperature reaching a maximum of approximately $15 \%$ Sn at the eutectic temperature (Figure 9 and 10). The limit of this solubility decreases to less than $14 \%$ sn 


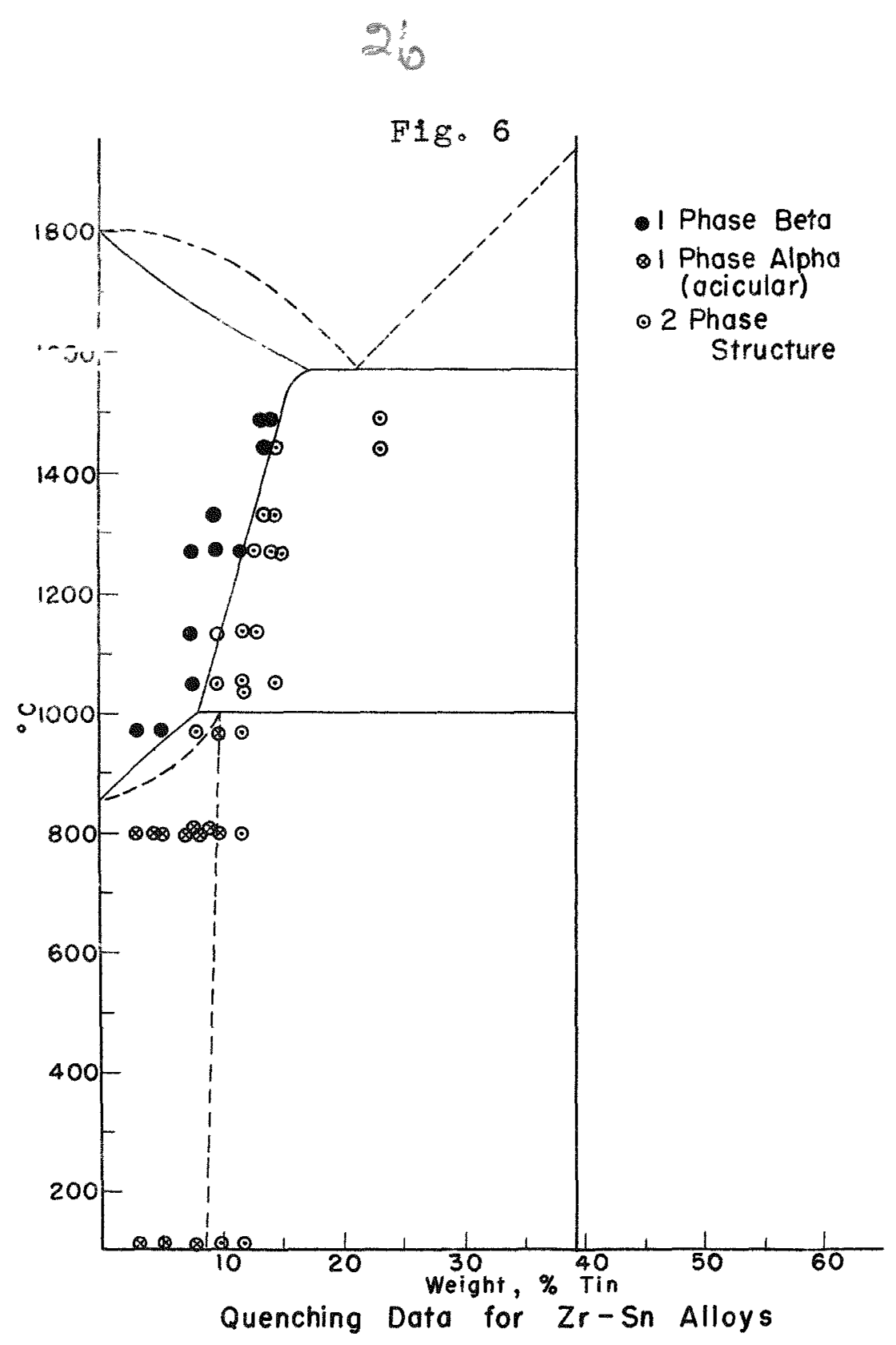




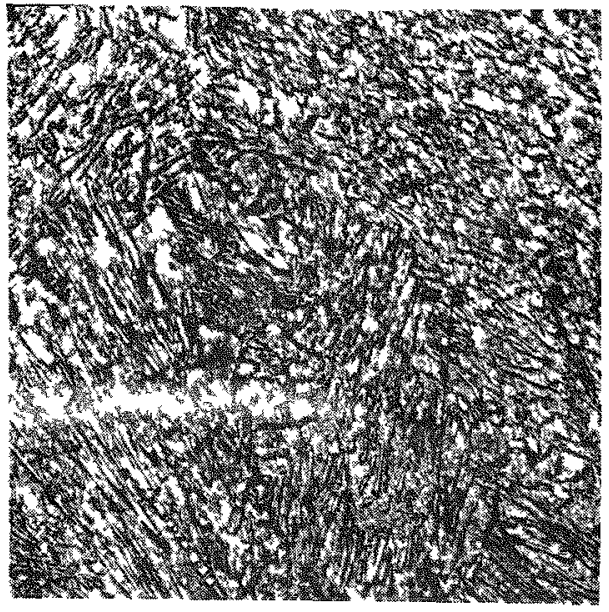

Fig。 7。Tin-Zirconium Alloy。 20.9 per cent tin. Eutectic。 All samples etched with $1 \% \mathrm{HF}$ $+\mathrm{HNO}_{3} .250 \mathrm{X}_{0}$

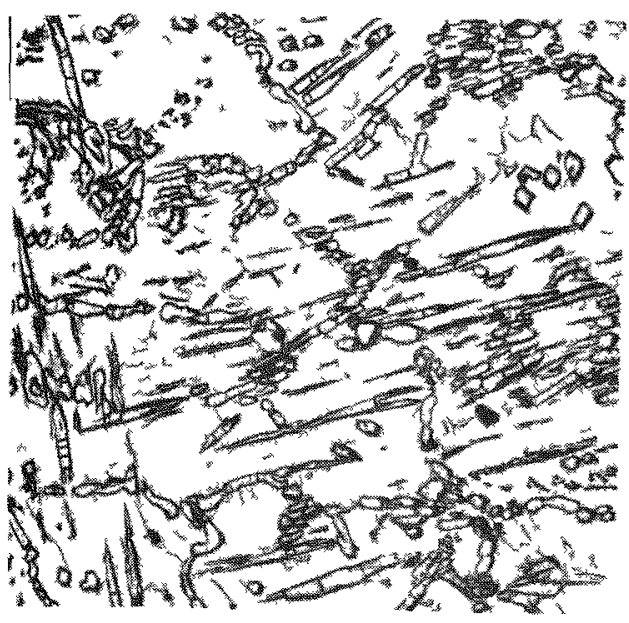

Fig. 9。Tin-Zirconium Alloy。 18.5 per cent tin. Two phases quenched from $1500^{\circ} \mathrm{C}$. $150 \mathrm{X}$

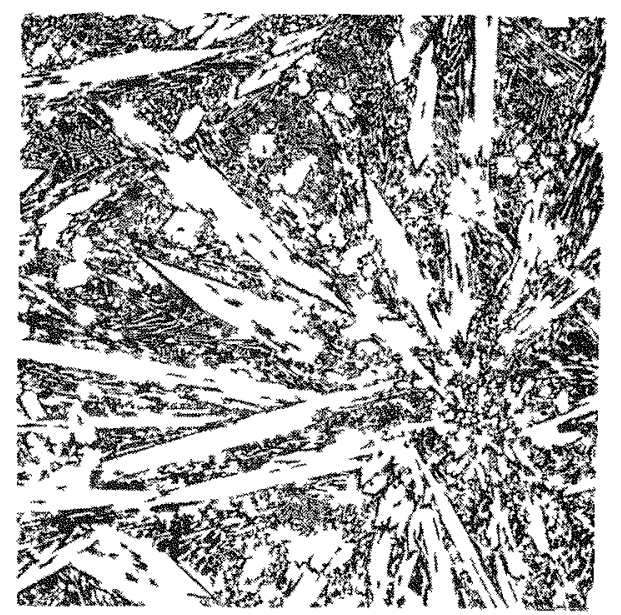

Fig。 8. Tin-Zirconium Alloy. 29.4 per cent tin. As cast. Eutectic plus compoundo $150 \mathrm{X}$.

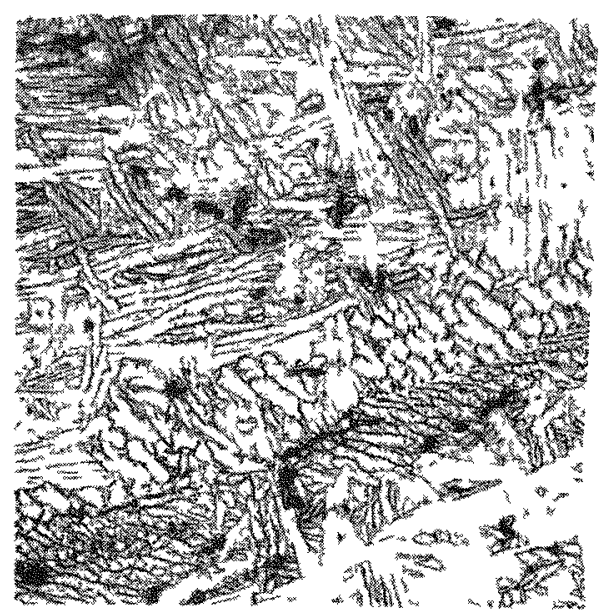

Fig。 10. Tin-Zirconium Alloy. 13.9 per cent tin. Quenched from $1500^{\circ} \mathrm{C}$ o one phase alloy. $150 X_{\infty}$ 
at $1445^{\circ}$ (Figure 11 and 12 ), and to less than $12.5 \%$ at $1275^{\circ} \mathrm{C}$ (Figure 13 and 14). At the peritectoid temperature, $1010^{\circ} \mathrm{C}$, the maximum beta solubility is more difficult to assign from quenching data. Since the alpha-beta transformation has been raised however, the solubility in alpha must be greater than in beta. which fact along with the thermal data tend to place the solubility of tin in beta zirconium at about $8 \%$ at the perotectoid.

The alpha solid solution region has also been investigated by quenching and by X-ray studies. From a maximum of approximately 10\% Sn at the peritectoid the solubility decreases slightly lying close to $10 \% \mathrm{sn}$ at $800^{\circ} \mathrm{C}$ (Figures 15 and 16 ) and at 7 to $8 \%$ at room temperature. These limits are subject to considerable error however; the presence of the carbide phase makes differentiation between one and two phase structures somewhat difficult. There is also the question of whether complete equilibrium has been attained aince precipitation of the compound phase from solid solution does not take place unless the alloy has been cooled very slowly. In the alloys as cast, one phase structures are retained in alloys containing as high as $12.7 \%$ sn but upon cooling from $1000^{\circ} \mathrm{C}$ to room temperature over \& 36 hour period precipitation has been observed in the 9.7\% alloy (Figure 17 and 18).

$X$-ray studies made in the alpha region support the above conclusions. A series of alloys prepared by identical procedures differing only in tin content were examined to estabilish the effect of tin upon the lattice constants of zirconium. Precision pictures were taken with a self focusing back reflection camera on this series which had been prepared from Hafnium free grade A crystal bar and contained carbon as the major impurity. The results of these measurements are given in Table VIII。 The calculations of the lattice constants from $\sin ^{2} \theta$ values were refined by means of cohen's analytical extrapolation method.

Table VIII

\begin{tabular}{llll}
\hline \hline Sample & $\mathrm{a}_{\mathrm{O}}$ (A) & \multicolumn{1}{c}{$\mathrm{c}_{\mathrm{O}}$ (A) } & Impurity \\
\hline Iiterature & $3.228 \pm .001$ & $5.140 \pm .001$ & Hf \\
Crystal bar Zr & $3.2264 \pm .0001$ & $5.139 \pm .001$ & $2400 \mathrm{ppm} \mathrm{C}$ \\
$1.94 \% \mathrm{Sn}$ & 3.2239 & 5.141 & $1300 \mathrm{ppm} \mathrm{C}$ \\
$5.0 \% \mathrm{ppm} \mathrm{C}$ \\
\hline
\end{tabular}




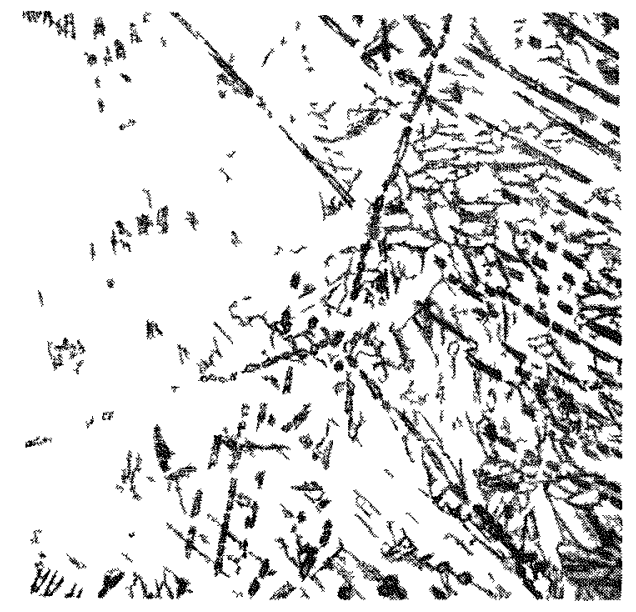

Fig. 11. Tin-Zirconium Alloy 13.9 per cent tin. Quenched slowly from $1445^{\circ} \mathrm{C}$. Undissolved compound appears as dark phaso. $250 \mathrm{x}$.

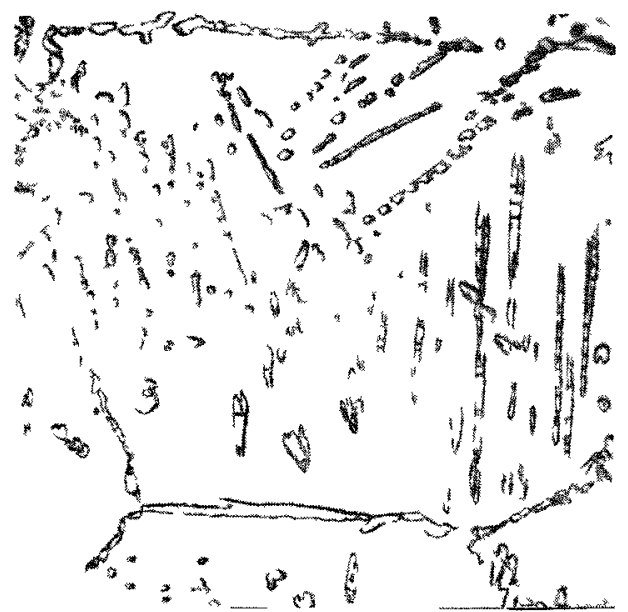

Fig. 13. Tin-Zirconium Alloy . 14.0 per cent tin. Quenched from $1275^{\circ} \mathrm{C}$. Precipitated compound in zirconium solid solution background.

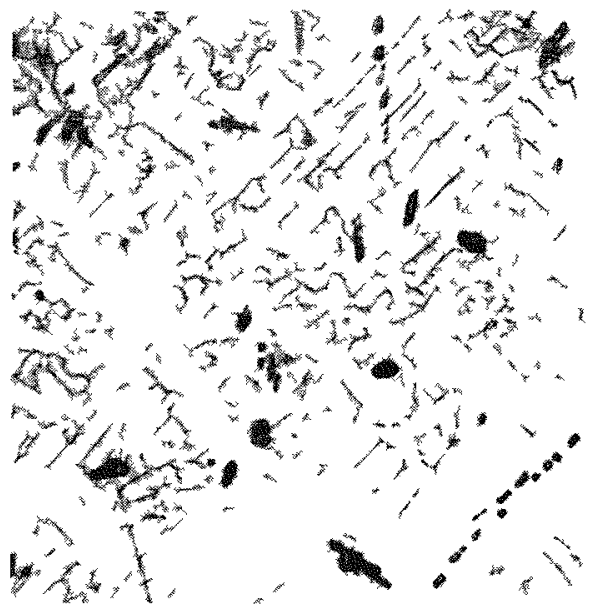

Fig. 12。 Tin-Zirconium Alloy. 13 per cent tin. Quenched from $1445^{\circ} \mathrm{C}$. One phase alloy o $250 \mathrm{X}$.

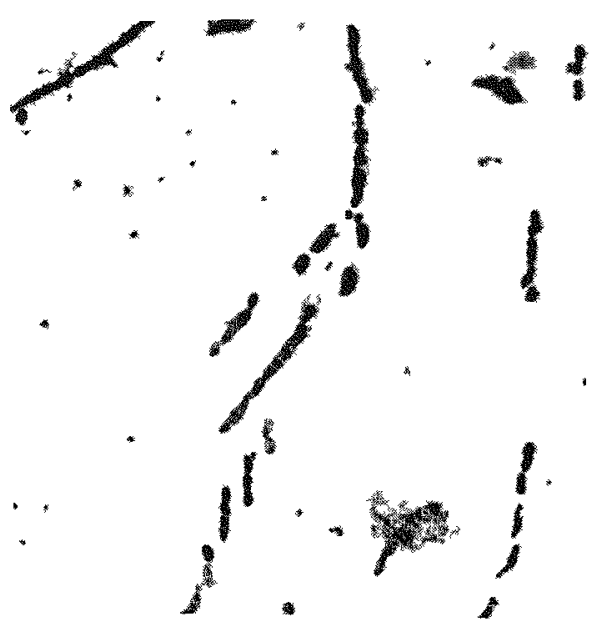

Fig. 14。 Tin-Zirconium Alloy. 11.4 per cent tin. Quenched from $1275^{\circ} \mathrm{C}$. one phase alloy except for carbide along the grain boundaries. 


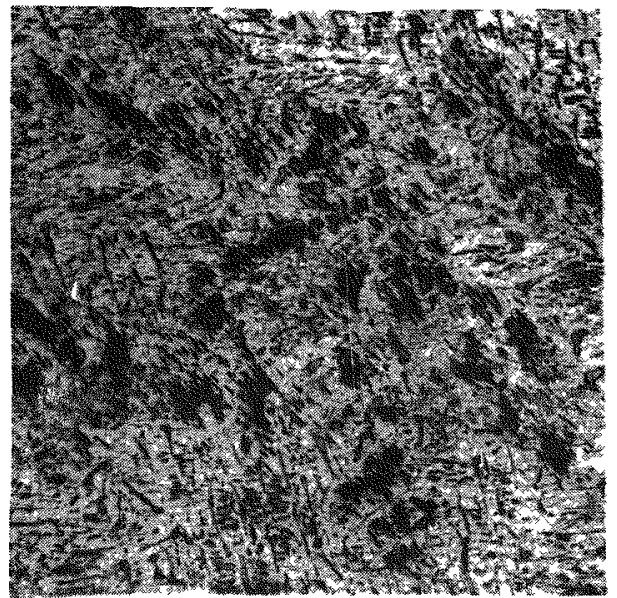

Fig。15。Tin-Zirconium Alloy。 11.4 per cent tin. Quenched from $800^{\circ} \mathrm{C}$. A second phase appears as fine precipitate. $250 \mathrm{x}$.

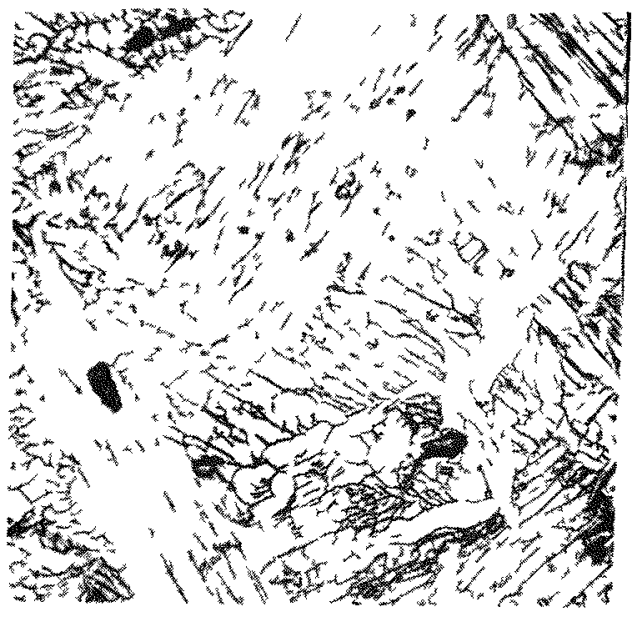

Fig. 17。 Tin-Zirconium Alloy。 12.7 per cent tin. As cast alloy showing single phase appearance. $250 \mathrm{x}$.

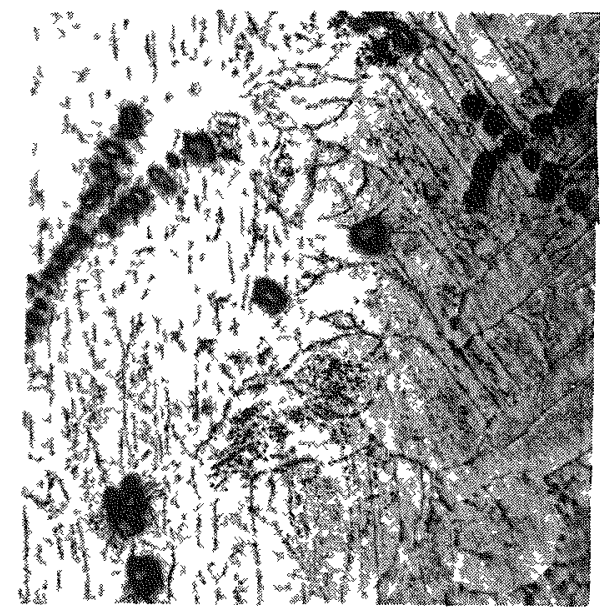

Fig。16。 Tinozirconium Alloy。 9.7 per cent tin. Quenched from $800^{\circ} \mathrm{C}$ one phase except for presence of carbide structure $150 \mathrm{X}$ 。

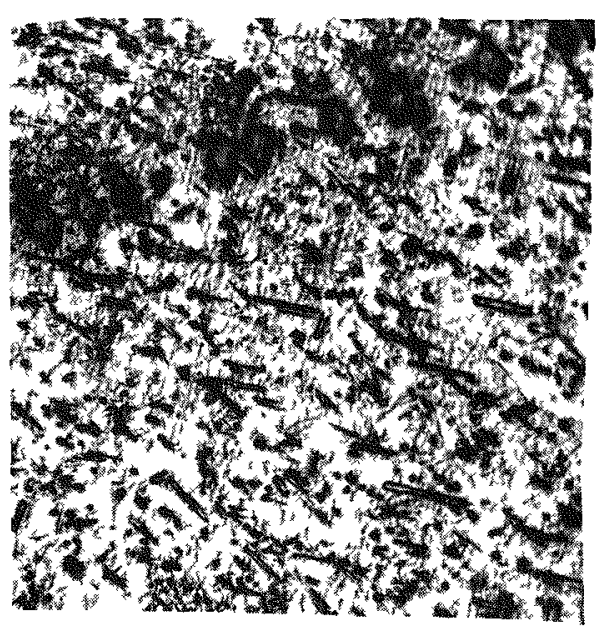

Fig。 18, Tin-Zirconium Alloy. 9.7 per cent tino Annealed and cooled very slowly. Small compound needles have precipitated during annealing. 250X. 
The a. value, it can be seen, is decreased by .015 Angstroms whereas the $z$ parameter, $c_{0}$, is almost unchanged. The cell contraction on addition of tin points to a substitutional type solubility in which the smaller radius tin atoms replace the somewhat larger zirconium atoms.

Future work will include determination of the structures of the compounds by $X$-ray diffraction studies and refinement of the solid solubility limits.

J. Zirconium-Niobium Alloys (B。A.Rogers, E.S.Hodge, G。E. Faulkner, R.E.Kleint, D.I. Harrington, J.E。Ross and G.Iso Stocking)。

A tentative phase diagram, shown as Figure 19, has been constructed for the zirconium-niobium alloy system up to 25 per cent niobium. Alloys up to 35 per cent niobium have been heat treated, and alloys from 40 to 100 per cent niobium have been, prepared but not yet studied.

Bureau of Mines zirconium sponge was heated to about $1500^{\circ} \mathrm{C}$ for a period of from 3 to 4 hours, depending on the amount of sponge, under a vacuum of about 0.2 micron in order to distill off some of the impurities. The purified sponge resulting from this treatment was pressed together with small pieces of sheet niobium obtained from the Fansteel Metallurgical corporation. The tablet thus obtained was melted in a tungsten electrode arc furnace under atmospheric pressure of purified helium. In the early stages of the investigation, nioblum powder, obtained from the Fansteel Metallurgical Corporation, was used in making a.11oy specimens. However, the powder contained about 0.5 per cent impurities, mainly tantalum and carbon. Therefore, niobium sheet, which contained only traces of impurities according to analyses supplied by the company, was used subsequently. Usually, button-shaped ingots weighing about 70 grams were prepared. As a means of improving their homogeneity, the buttons were remelted after being inverted.

The solidus line has been established up to 40 per cent niobium by means of melting-point data. A small-diameter, shallow hole was drilled at the mid-point of and at right angles to the longitudinal axis of a $\frac{1}{4}$ inch diameter by $3 \frac{1}{2}$ inch long, swaged alloy rod. A high current passed through the rod caused it to heat. When molten material appeared in the hole the temperature was determined. With an optical pyrometer. 


\section{2}

Fig。 19

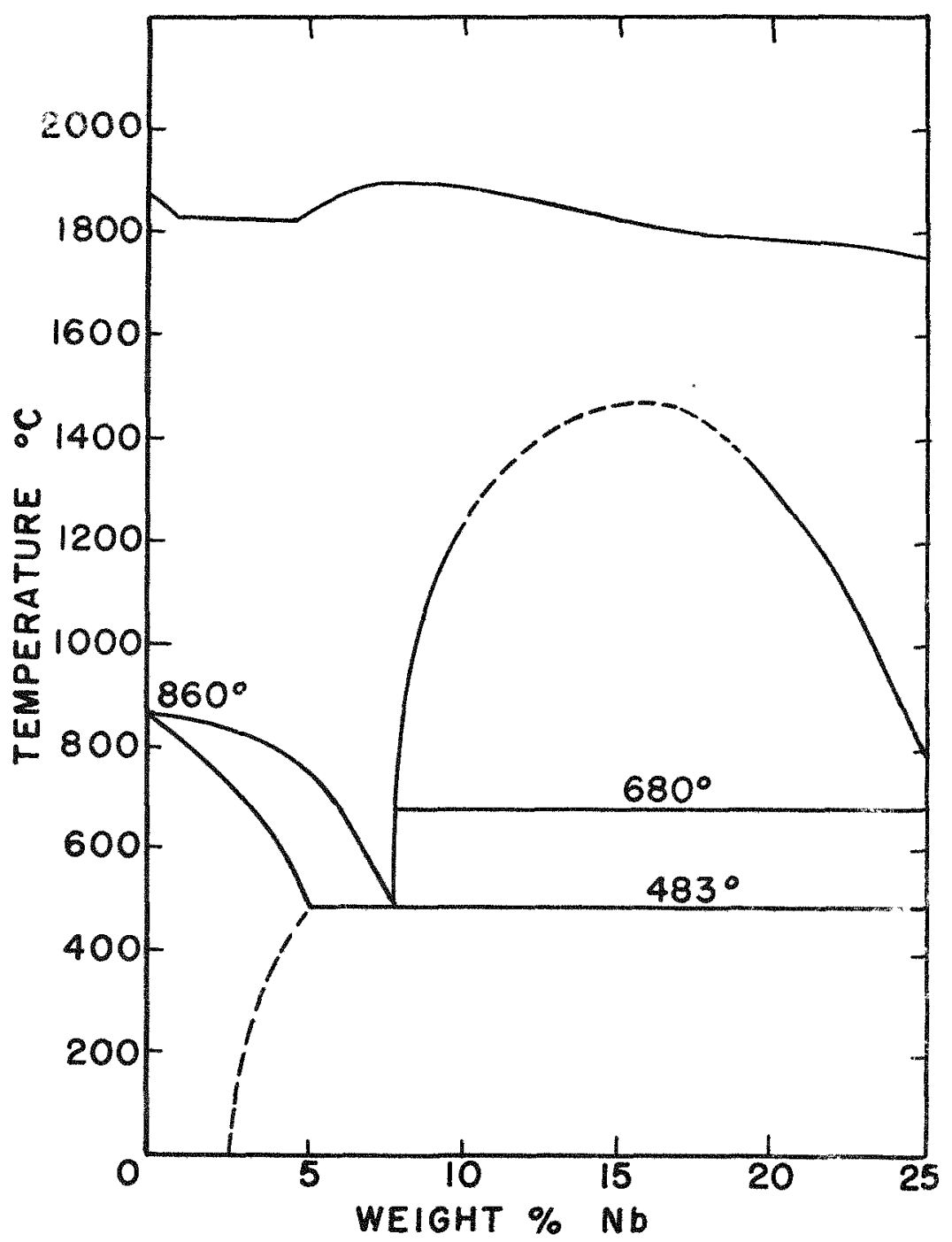

Tentative Zirconium-Niobium Phase Diagram 
One method of determining transformation points was by microscopic study of specimens quenched from successively lower temperatures. Quenching temperatures of $1200,930,900,850$, $750,700,650,600,550,500,450,400^{\circ} \mathrm{C}$ were used. The specimens which were quenched at $900^{\circ} \mathrm{C}$ or lowex were a.11 heated to between 925 and $950^{\circ} \mathrm{C}$, slowly cooled to the quenching temperature and then quenched in 011 . Those quenched from above $900^{\circ} \mathrm{C}$ were heated to about $1500^{\circ} \mathrm{C}$ and slowly cooled to the quenching temperature before being plunged into the oil bath. The heating and quenching were carried out at pressures between 0.02 and 0.04 micron.

Photomicrographs showing the structure of the 1 and 2.5 per cent niobium alloys quenched from $650^{\circ} \mathrm{C}$, the 5 per cent alloy quenched from $550^{\circ} \mathrm{C}$ and the 10 per cent a $110 y$ quenched from $1000^{\circ} \mathrm{C}$ are shown as Figures 20, 21, 22, and 23 respectively.

Thermal arrests were found from curves obtained with a differential thermocouple connected to a Leeds and Northrup X-Y recorder. In this procedure a nickel standard specimen and an a.lloy specimen of equal volume, were placed in a $1 \frac{1}{4}$ inch $O . D$. silica tube, and the assembly placed in an electrical resistance furnace. Plotting of the heating and cooling differential curves between the two specimens was enabled by the following circuit. The differential thermocouple was connected so that Alumel wires extended from the alloy specimen and the nlckel standard to the $Y$ terminals of the recorder and a chromel of wire connected the two specimens. In order for the null point to come midway on the vertical axis of the strip chart of the recorder an external EMF of 5 miliivolts was impressed on the circuit. This gave an effective range of 10 miliivolts, 5 milivolts on either side of the neutral position on the chart. At the same time another thermocouple enabled the temperature inside of the silica tube to be plotted along the $\mathrm{X}$ axis of the recordex. The thermal data. were obtained under a vacuum of from 0.04 to 0.1 micron.

Some X-ray data and hardness tests were also used to check the data obta. Ined from the thermal studies and from the microstructure of the alloys. Some of the results of the hardness tests are Iisted in Table IX and Table X. In Table IX the abrupt change in hardness between the specimens quenched from $700^{\circ} \mathrm{C}$ and those quenched from $650^{\circ} \mathrm{C}$ presumably is a result of the a.11oy transformation at $680^{\circ} \mathrm{C}$. In Table $\mathrm{X}$ the limit of solid solubility at about $600^{\circ} \mathrm{C}$ is evidenced by the change in hardness between the 4 and 5 per cent niobium alloys.

In general the alloys can be swaged, rolled, drilled and otherwise machined readily. Total reductions in thickness of 96 per cent have been obtained with the 1 and 2 per cent niobium 


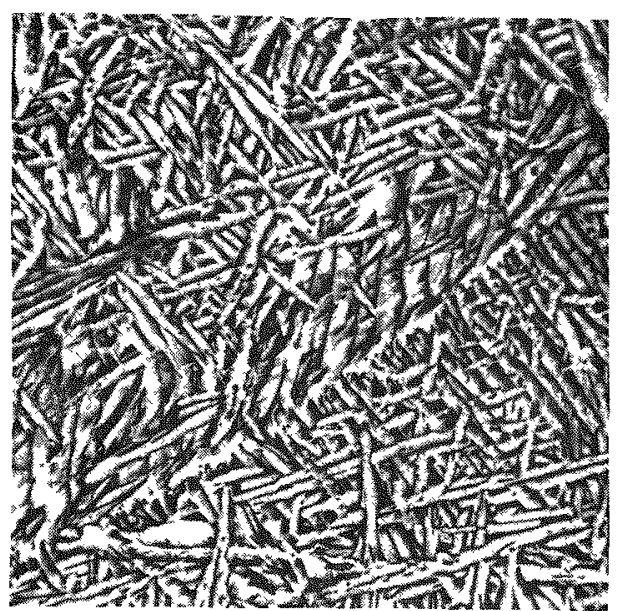

Fig。20。 ZirconiumeNiobium Alloy. 1 per cent Nioblumo Quenched in oll from $6500 \mathrm{C}$. 250X. Etched with $\mathrm{Hf}+\mathrm{HCl}+\mathrm{H}_{2} \mathrm{O}$.

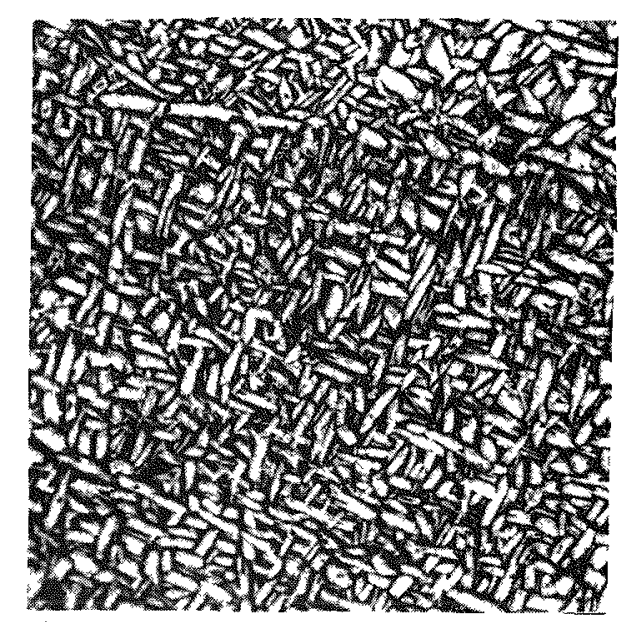

Fig。21。 Zirconium Niobium Alloy. 2.5 per cont niobium. Quenched in 011 from $650^{\circ} \mathrm{C}$. 250X。 Etched with $\mathrm{Hf}+\mathrm{HCI}+\mathrm{H}_{2} \mathrm{O}$ 。

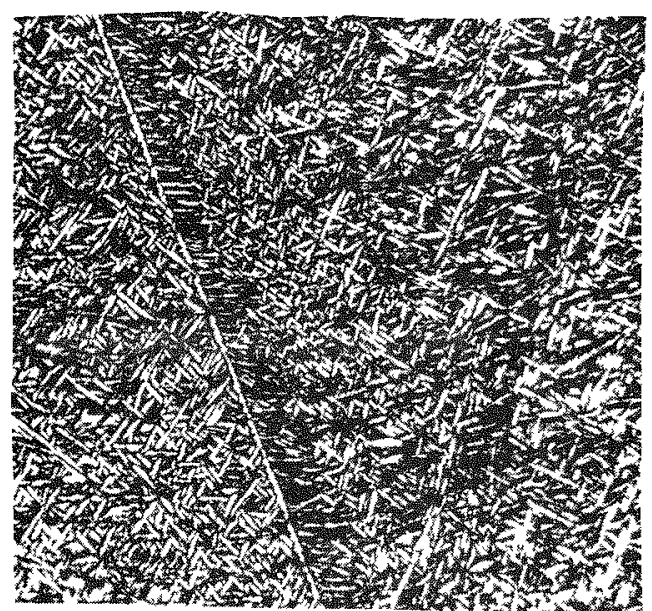

Fig, 22。 Zirconium Niobium Alloy. 5 per cent nioblum. Quenched in oil from $550^{\circ} \%$ 250X. Etched with $\mathrm{Hf}_{4}+\mathrm{HNO}_{3}$ 。

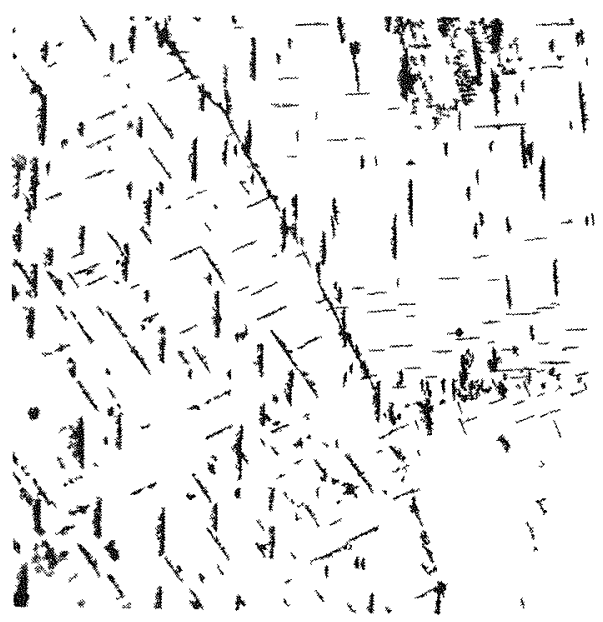

Figo 23. Zirconium-Niobium Alloy。 10 per cent niobium. Quenched in 011 from $1000^{\circ} \mathrm{C}$.

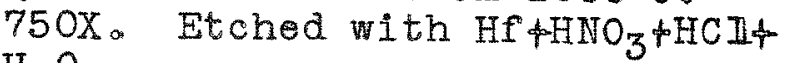
$\mathrm{H}_{2} \mathrm{O}$. 
Table IX

Hardness of Two Zirconium-Niobium Alloys Quenched from Different Temperatures

\begin{tabular}{|c|c|c|c|}
\hline \multicolumn{2}{|c|}{6 per cent niobium alloy } & \multicolumn{2}{|c|}{ IO per cent niobium a.IIoy } \\
\hline $\begin{array}{l}\text { Quenching } \\
\text { temperature } \\
{ }_{\mathrm{C}}\end{array}$ & $\begin{array}{l}\text { Hardness } \\
\text { Rockwell A } \\
\text { scale }\end{array}$ & $\begin{array}{l}\text { Quenching } \\
\text { temperature } \\
{ }_{\mathrm{O}}\end{array}$ & $\begin{array}{l}\text { Hardness } \\
\text { Rockwe11 A } \\
\text { scale }\end{array}$ \\
\hline $\begin{array}{l}930 \\
900 \\
750 \\
700 \\
650 \\
600 \\
500 \\
450\end{array}$ & $\begin{array}{l}65 \\
64.5 \\
65 \\
65.5 \\
56.5 \\
56 \\
57 \\
52.5\end{array}$ & $\begin{array}{r}1200 \\
930 \\
900 \\
850 \\
750 \\
700 \\
650 \\
600 \\
550 \\
500 \\
400\end{array}$ & $\begin{array}{l}66.5 \\
62 \\
62.5 \\
63 \\
63.5 \\
63 \\
57.5 \\
57 \\
56.5 \\
54.5 \\
55\end{array}$ \\
\hline
\end{tabular}

Table $\mathrm{X}$

Hardness of Several Zirconium-Niobium Alloys Quenched from $600^{\circ} \mathrm{C}$

\begin{tabular}{cc}
\hline Niobium, per cent & Hardness, Rockwell A scale \\
\hline 1 & 48 \\
2 & 48.5 \\
3 & 49 \\
4 & 48.5 \\
5 & 54.5 \\
6 & 55.5 \\
\hline
\end{tabular}


alloys by a combination of hot and cold-rolling. The steel-jacketed specimen can be hot-rolled to about 40 per cent reduction, the jacket removed, and the slab reduced over 50 per cent more by coldrolling. Cold reduction of about 80 per cent in area has been obtained by swaging the 1 and 2 per cent niobium alloys.Wire 0.031 inch in diameter has been made from these alloys.

Some of the tensile properties have been determined on the annealed 1 and 2 per cent niobium alloys. It was noted that the ultimate strength increased greatly as the rate of stressing the specimen increased. The data shown in Table XI were obtained at a rate of stressing of 0.01 inch per minute. A rather low capacity

Table XI

Tensile Properties of Two Zirconium-Niobium Alloys

\begin{tabular}{ccccc}
\hline $\begin{array}{c}\text { Niobium } \\
\text { per cent }\end{array}$ & $\begin{array}{c}\text { Yield strength } \\
\text { psi }\end{array}$ & $\begin{array}{c}\text { Ultimate strength } \\
\text { psi }\end{array}$ & $\begin{array}{c}\text { Elongation Modulus of } \\
\text { per cent }\end{array}$ \\
\hline 1 & 45,000 & 54,000 & 62 & $15,000,000$ \\
2 & 61,000 & 66,000 & 62 & $15,000,000$ \\
\hline
\end{tabular}

* for 0.2 per cent total elongation

for work hardening is evidenced by the relatively small difference between the yield strength and the ultimate strength. Hardness tests on the specimens in the hot worked condition compared with similar tests on the same specimen after being cold worked seem to verify this.

Some data regarding the corrosion resistance of these alloys in singly-distilled, air-saturated water at $315^{\circ} \mathrm{C}$ are included in Table XII. These data were obtained from alloy specimens made from Bureau of Mines zirconium sponge and Fansteel Metaliurgical Corporation niobium powder. 
Table XII

Corrosion Rates for Some Zirconium-Niobium Alloys in Distilled. Water at $315^{\circ} \mathrm{C}$

\begin{tabular}{lll}
\hline \hline $\begin{array}{l}\text { Niobium } \\
\text { per cent }\end{array}$ & $\begin{array}{c}\text { Time of Run } \\
\text { hours }\end{array}$ & $\begin{array}{c}\text { Corrosion Rate } \\
\mathrm{mg} / \mathrm{cm}^{2} / \mathrm{mo}\end{array}$ \\
\hline 5 & 224.5 & 3.0 \\
5 & 263.8 & 2.1 \\
4 & 263.8 & 3.5 \\
3 & 263.8 & 2.0 \\
2.5 & 263.8 & 1.9 \\
2.5 & 130.2 & 3.0 \\
2.0 & 263.8 & 7.4 \\
1.0 & 130.2 & 2.0 \\
.5 & 263.8 & \\
\hline
\end{tabular}

K. Antimony-Zirconium Alloys (D。Peterson, R。Russi)。

Because of the relatively low neutron capture cross section of antimony, about two per cent can be alloyed with zirconium without contributing unduly to the total cross section of the alloy. The effects of antimony additions on the corrosion behavior of zirconium are being investigated.

The alloys could not be prepared by ordinary co-melting of the two metals because of the low boling point $\left(1380^{\circ} \mathrm{C}\right)$ of antimony. Even under atmospheric pressure at temperatures slightly above $800^{\circ} \mathrm{C}$ diffusion experiments were difficult to perform because of the high volalility of the antimony.

Alloys made by bomb reduction proved to yield a much lower per cent of $\mathrm{Sb}$ than that added to the charge. The alloys formed in graphite lined bombs showed a relatively higher percentage of antimony than alloys formed in oxide liners, but this difference could be due to the lower metal yields obtained in the graphite liners.

It was found that by sealing a charge of sponge zirconium and antimony in a stainless steel pipe, raising the temperature to $900^{\circ} \mathrm{C}$, and allowing the antimony to diffuse into the zirconium 
for about 24 hours that the resultant alloy could be melted with a low loss of $\mathrm{Sb}$, provided the $\mathrm{Sb}$ content was below that of the compound.

The compound was isolated in this manner. An excess of $\mathrm{Sb}$ was added to the Zr and allowed to react. Then the mixture was cast under vacuum and the $\mathrm{Sb}$ in excess of the compound was boiled off. By the initial weight of metal added and loss in weight due to evaporization of $\mathrm{Sb}$ it was found that the compound is about the composition of $\mathrm{Zr} \mathrm{Sb}$. The analytical results are not yet available so this stoichiometric formula has not yet been definitely established. Investigation of the crystal structure of the compound is now being done.

By running ordinary cooling curves no transformations are evident in this system. However by the use of a differential cooling curve run on an $\mathrm{X}-\mathrm{Y}$-recorder a break was picked up around 900 to $925^{\circ} \mathrm{C}$ on the $1.6 \%$ antimony in zirconium.

TabIe XIII

\begin{tabular}{|c|c|c|c|c|c|}
\hline $\begin{array}{l}\text { Corrosion } \\
\text { No. }\end{array}$ & Added & $d \% \mathrm{sb}$ & Actual $\%$ Sb & Hrs. of Corro & $\begin{array}{c}\text { Rgte } \\
\mathrm{mg} / \mathrm{cm}^{2} / \text { month }\end{array}$ \\
\hline $\begin{array}{l}A-224 \\
A-223 \\
A-249 \\
A-249 \\
A-250 \\
A-250 \\
A-251 \\
A-251 \\
A-252 \\
A-252\end{array}$ & $\left.\begin{array}{r}5 \\
10 \\
0.5 \\
0.5 \\
0.5 \\
0.5 \\
5.0 \\
5.0 \\
1.0 \\
1.0\end{array}\right\}$ & 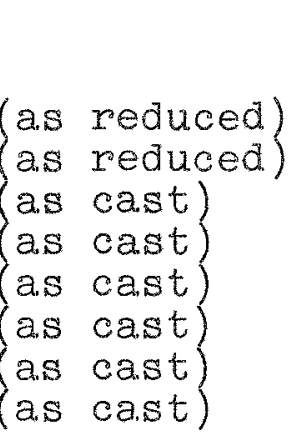 & $\begin{array}{c}\text { not known } \\
1.6 \\
.07 \\
.07 \\
.07 \\
.07 \\
.44 \\
.44\end{array}$ & $\begin{array}{l}501 \\
501 \\
136 \\
274 \\
136 \\
274 \\
136 \\
274 \\
136 \\
274\end{array}$ & $\begin{array}{l}4.7 \\
0.32 \\
\text { high } \\
\text { high } \\
4.4 \\
5.0 \\
0.21 \\
0.21 \\
0.12 \\
0.29\end{array}$ \\
\hline
\end{tabular}

Corrosion tests on severa. samples show that the addition of antimony in sma.11 amounts reduces the corrosive tendencies in $600^{\circ} \mathrm{F}$ water markedly (Table XIII)。It is not known whether the smal1 amount of $\mathrm{Sb}$ that gets into the $\mathrm{Zr}$ is responsible for the increase in corrosion resistance of whether the $\mathrm{Sb}$ acts as a scavenger to take undesirable impurities from the Zro 
Quenching experiments and microstudies are also being made on the high zirconium end of the binary system in order to obtain data for the phase diagram.

\section{Zirconium-Carbon System (P。Chiotti)。}

An attempt has been made to determine the liquidus curve for the zirconium-carbon system, Bureau of Mines zirconium sponge metal was heated to various temperatures in a graphite crucible and held at temperature for approximately 25 minutes. The samples thus prepared were then cooled to room temperature and the center portion of the charge analysed for carbon content. The results obtained are given in Table XIV。

Table XIV

Carbon Content of Zirconium Heated in contact with Carbon

\begin{tabular}{cccc}
\hline Sample & $\begin{array}{c}\text { Temperature } \\
\text { OC }^{-}\end{array}$ & $\begin{array}{c}\text { Time at } \\
\text { Temp. Minutes }\end{array}$ & $\begin{array}{c}\text { Weight \% } \\
\text { Carbon }\end{array}$ \\
\hline 1 & $1820-1830$ & 25 & 0.35 \\
2 & $1920-1935$ & 25 & 0.48 \\
3 & $1950-1970$ & 25 & 0.47 \\
4 & $2070-2100$ & 25 & 0.56 \\
5 & $2135-2145$ & 25 & 0.78 \\
6 & $2330-2370$ & 25 & 1.98 \\
7 & $2545-2565$ & 26 & 2.81 \\
8 & $2690-2710$ & 25 & 3.70 \\
9 & $2790-2800$ & 15 & 4.40 \\
10 & $2845-2855$ & 14 & 19.15 \\
\hline
\end{tabular}

The microstructure of sample (10) heated to above $2800^{\circ} \mathrm{C}$ shows a. very definite eutectic structure. Sample (9) heated at 2790 $2800^{\circ} \mathrm{C}$ showed a structure of carbide dendrites in a metal matrix; the region in direct contact with the graphite crucible showed that a small amount of eutectic had formed indicating that the eutectic temperature is approximately $2800^{\circ} \mathrm{C}$. On the basis of these observations the eutectic temperature has been approximated 
at $2800 \pm 50^{\circ} \mathrm{C}$. The sample heated to $1820-1830^{\circ} \mathrm{C}$ had definitely melted and chemical analysis gave a carbon content of 0.35 weight per cent. This would indicate that small amounts of carbon lowers the solidus temperature. Further work will be done to determine whether this lowering of the melting point of zirconium is actually due to carbon. All the other alloys listed in Table XIV have a dendritic structure.

Table XV

Thermal Analyses of Zirconium-Carbon Alloys

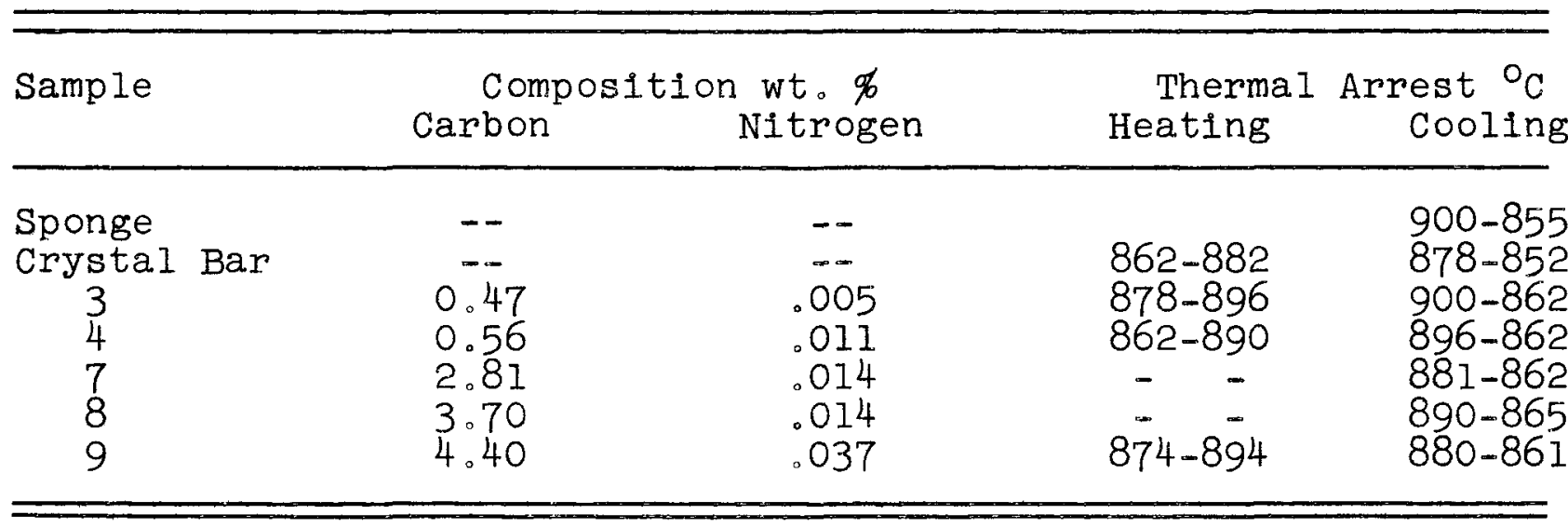

Differential thermal analyses show no definite change in the transition temperature. The data obtained is shown in Table XV。 The heating and cooling rate was approximately $10^{\circ} \mathrm{C} / \mathrm{min}$, and the system was maintained at a pressure of 0.1 to 0.02 microns of mercury. The temperature difference between the specimen and a neutral body of nickel was measured.

The zirconium sponge used shows a transformation range of approximately $45^{\circ} \mathrm{C}$. This is believed to be due to oxygen and nitrogen in the sponge as received and to small amounts picked up during thermal analysis.

$X$-ray analyses of sample (10) gave a lattice constant for $\mathrm{ZrC}$ of $4.6958 \mathrm{~A}$ and sample (8) which consisted of carbide dendrites in a zirconium matrix gave a lattice constant of $4.709 \mathrm{~A}$ for the carbide. This variation may be due to solid solubility of either carbon or zirconium in the monocarbide. Further work will be done to determine the limits of solid solubility. Further work will be done on this system. 
M。 Zirconium-Oxygen System (P.Chiotti)。

Some preliminary work has been done on this system. The change in electrical resistance with temperature of a number of samples of crystal bar containing varying amounts of impurities was measured in order to determine their probable effect on subsequent studies of the zirconium-oxygen system, and in particular the effect of these impurities on the zirconium transformation temperature.

The method used in measuring the change in electrical resistance with temperature is described in ISC-103. During these measurements a vacuum of 0.003 to .02 microns of mercury was maintained in the system, with the exception of runs with samples 2 and 7 , Table XVI,

Table XVI

Transformation in Zirconium Crysta.1 Ba.r

\begin{tabular}{|c|c|c|c|c|c|c|}
\hline Sample & $\begin{array}{c}\text { Chemical } \\
N\end{array}$ & $\begin{array}{c}\text { Analysis, ppm } \\
\text { Fe }\end{array}$ & $\begin{array}{l}\text { Trans } \\
\text { Hea } \\
\text { Start }\end{array}$ & $\begin{array}{l}\text { ormation } \\
\text { ing } \\
\text { Finish }\end{array}$ & $\begin{array}{r}\text { Temp } \\
\text { coo } \\
\text { Start }\end{array}$ & $\begin{array}{l}\text { ing } \\
\text { Finish }\end{array}$ \\
\hline$I$ & 75 & 4540 & 780 & 870 & 860 & 760 \\
\hline 2 & 89 & 3370 & 800 & 900 & 890 & 790 \\
\hline 3 & 446 & 1434 & 830 & 930 & 890 & 800 \\
\hline 4 & 61 & 300 & 790 & 880 & 870 & 800 \\
\hline 5 & 76 & 242 & 865 & 890 & 880 & 850 \\
\hline 6 & 165 & 125 & 830 & 885 & 872 & 825 \\
\hline 7 & 363 & 83 & 855 & 960 & 940 & 855 \\
\hline
\end{tabular}

in which case the pressure varied from 0.02 to 0.1 and 0.04 to 0.1 microns respectively. The average heating or cooling rate through the transformation range was maintained at approximately $1^{\circ} \mathrm{C}$ per minute. The results obtained are given in Table XVI.

Chemical analyses shows varying amounts of nitrogen and iron which in part explain the variation observed. These same samples are also to be analysed for oxygen content. Sample 1 was a.lso checked by thermal analysis and the results obtained agree very closely with those given in the Table. 
It is evident that the lowering of the transformation temperature is definitely related to the amount of iron in the samples and that even very small amounts produce an appreciable effect.

An attempt was also made to obtain diffusion bands between zirconium dioxide and zirconium by heating the metal in contact with the oxide. A small plece of massive metal was tightly packed. in zirconia powder and then heated in a graphite crucible by means of an induction furnace. The diffusion bands obtained indicated the existence of a eutectic with a melting point of about $1700^{\circ} \mathrm{C}$ as previously reported. However, X-ray powder diffraction patterns taken on material from the surface of the zirconium showed considerable contamination by ZrC. An alloy containing approximateIy 50 atomic per cent oxygen was then prepared by the arc fusion method. In this case the alloy obtained consisted of well formed dendrites in a $\mathrm{Zr}-\mathrm{O}$ solid solution and no evidence for eutectic formation could be observed.

Work on this sytem will also be continued.

N. Germanium-Zirconium Alloys (O.N. Carlson, and P.E. Armstrong)。

The Ge-Zr system has been investigated by preparing alloys from Belmont powdered germanium and massive grade III reject crystal bar by induction and arc melting. Themal, microscopic, and $\mathrm{X}$-ray data have been taken. A tentative diagram is in Figure 24. Two compounds are indicated from $X$-ray data obtained from the $20,40,60$ and 80 per cent germanium alloys. The solid solubility limit of Ge in a.Ipha Zro is less than $1 / 2$ per cent. Eutectic and compound compositions have not been checked by chemical analysis and their melting points have not been determined accurately. Alloys containing more than 20 weight per cent germanium appear to be exceedingly hard and brittle. 


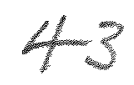

Fig。 24

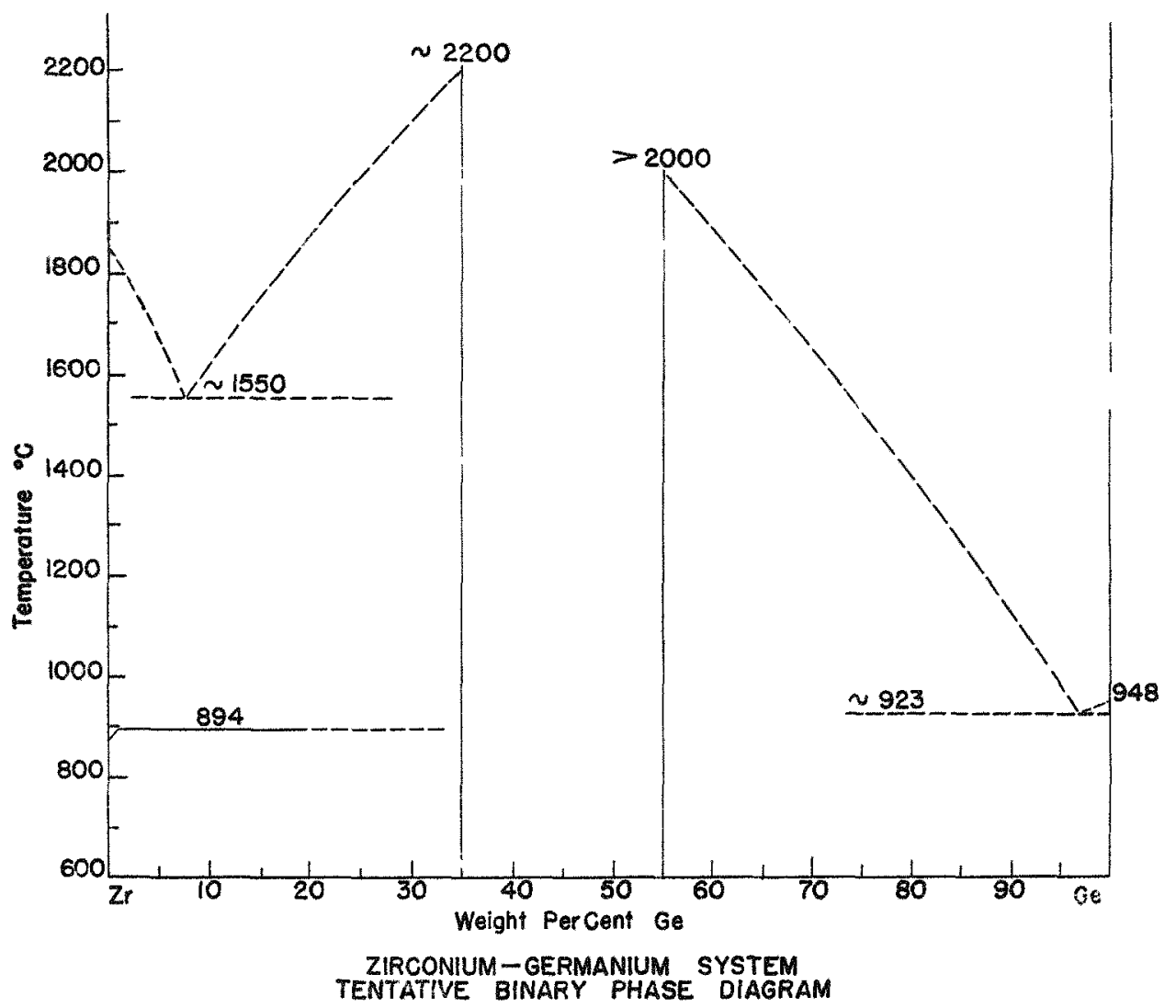


THORIUM

A. Experimental Bomb Reductions of Thorium Fluoride (K.A. Walsh)。

Modifications of the Ames reduction process for thorium metal are being tested. These changes are adaptations from the methods developed for zirconium, since the latter is quite susceptible to oxide contamination from the charge components or from the atmosphere. The usual process for thorium metal consists of a reduction of thorium fluoride by calcium in steel bombs lined with electrically fused dolomitic oxide. Zinc chloride is added to the reduction charge as a booster reagent and to supply an alloying addition of zine.

Substitution of zinc metal and iodine would increase the cost over that determined with the use of zinc chloride assuming no recovery of the iodine. This substitution would avoid oxide contamination resulting from the hygroscopic property of zinc chloride. Preliminary work on the experimental scale has emphasized the determination of the conditions giving a satisfactory yield of thorium metal. The quantity of iodine added to the experimental reduction charge has been varied and a maximum yield of thorium of 82 per cent was obtained A small scale reduction using the 
$2, \cdots+1$ 
C. Welding of Thorium (D Peterson)

A preliminary investigation was made of the problem of joining thorium metal to itself and to other metals. The use of silver solder was unsatisfactory because of the formation of a brittle phase in the joined area. Thorium sheet was successfully spot welded to itself and to tantalum and molybdenum sheet without the use of a protective atmosphere. Thorium sheet, $1 / 8$ inch thick, was butt welded to itself using an A.C.Heliarc welder with argon as a protective atmosphere. Ine welds were smooth and sound. A specimen was given a bend test over a radius of one and one half times the thrckness of the sheet and did not fracture when bent 180 degrees. Samples of the welded sheet were tested in tension. The welded area showed considerable elongation and the fracture occurred in the base metal outside the heat affected zone one sample of this welded sheet was cold rolled to 0,016 inch thick forl with no observed cracking in the welded area In a few cases cracking was observed in the weld during the first stages of cooling rhis was not a common occurrence and no reason for this behavior was found. Thorium sheets were also welded by the same technique to sheets of zirconium, titanium and tantalum. The weld in these cases did not appear to be as ductile as the parent metals but was sound and free from cracks or holes. 
D. Physical Properties of Thorium (B.A. Rogers, G. Murphy, G。E。 Faulkner, T。I。Jones, W。 No Miner and JoE, Ross)。

During recent weeks an investigation was started in order to collect data on a number of the physical and mechanical properties of thorium. Some of the tensile properties of thorium have been obtained at room temperature and at $600^{\circ} \mathrm{C}$. The yield strength for an offset of .002 inch drops from about 24,600 psi at room temperature to about $4400 \mathrm{psi}$ at $600^{\circ} \mathrm{C}$ 。 Withing the same temperature limit the modulus of elasticity drops from about 10,900,000 to $7,400,000$. Poisson's ratio at room temperature has been determined at 0.24 . An average value of $11 \times 10^{-6}$ has been obtained for the coefficient of thermal expansion from room temperature to $600^{\circ} \mathrm{C}$. Creep tests at room temperature and at $300^{\circ} \mathrm{C}$ are in progress but have not been run for a sufficient. length of time to obtain conclusive data.

A characteristic of thorium seems to be its ability to adhere to other metals. Evidence of this was obtained in a swaging test. In this test a 17/64 inch diameter hole was drilled along the longitudinal axis of a $5 / 8$ inch diameter thorium rod. A short length of $1 / 4$ inch O.D. soft, annealed, seamless steel tubing, with .035 inch thick walls, was inserted into the hole and the assembly swaged through a .425 inch die. Following the swaging operation an unsuccessful attempt was made to pull the steel tubing out of the thorium rod. The tubing ruptured at a point about 1/4 inch from the end of the thorium instead of coming out. Further evidence of this characteristic of thorium to stick to steel was obtained in the swaging operation itself. Considerable trouble was encountered during swaging when the thorium rod of ten seized in the dies. It appears, however, that the seizing may be alleviated by designing the dies with a relatively large amount of relief at the edges of the blade section.

E. Corrosion of Thorium (B.A.Rogers, J.T.Williams and L.O. Uhlenhopp)。

Studies of five specimens of thorium melted in beryllia and cast in graphite in the usual manner have shown excessive corrosion rates. Relatively large amounts of material flaked off the specimens during the test. The tests were conducted for a period of 88 hours in singly-distilled, air saturated water at $315^{\circ} \mathrm{C}$ 。 
All specimens were rough ground and then given a final grinding with No. 000 emergy paper followed in some cases with an etching treatment. Results of the tests are listed in Table XIX.

TabIe XIX

Corrosion of Thorium in water at $315^{\circ} \mathrm{C}$

\begin{tabular}{clc}
\hline Number & Condition of Specimen & $\begin{array}{c}\text { Corrosion rate, } \\
\text { Weight oss in } 88 \text { hr. } \\
\mathrm{mg} / \mathrm{cm}^{2}\end{array}$ \\
\hline 1 & As cast & 62.1 \\
2 & Cold-rolled to $80 \%$ reduction & 54.6 \\
3 & Same as 2 & 83.3 \\
4 & Same as 2 but etched with 50\% $\mathrm{HNO}_{3}$ and & 102. \\
5 & trace of HF & 208. \\
\hline
\end{tabular}

F。 Thorium Alloys (B.A. Rogers, D. Peterson, G。E。Faulkner and W.N. Miner).

Several binary alloys of thorium with various other metals have been prepared in a helium-filled, tungsten electrode arc furnace as part of a preliminary survey of this field in order to determine which alloys show sufficient promise to merit further investigation. Hardness values and some information regarding their ductility have been obtained. Generally, ingots weighing about 70 grams have been made, although 30 gram ingots were made of those alloys containing rare earths.

The alloys, their hardness values, and some information regarding their ductility are listed in Table XX.

Alloys of thorium with lead, tin, and molybdenum that had been prepared by arc melting were polished, etched and examined microscopically. The five per cent lead alloy appeared to be a one phase alloy. The five per cent tin, five per cent molybdenum and two per cent molybdenum alloys appeared to be two phase alloys. 
Table XX

Properties of Some Thorium-Rich Alloys

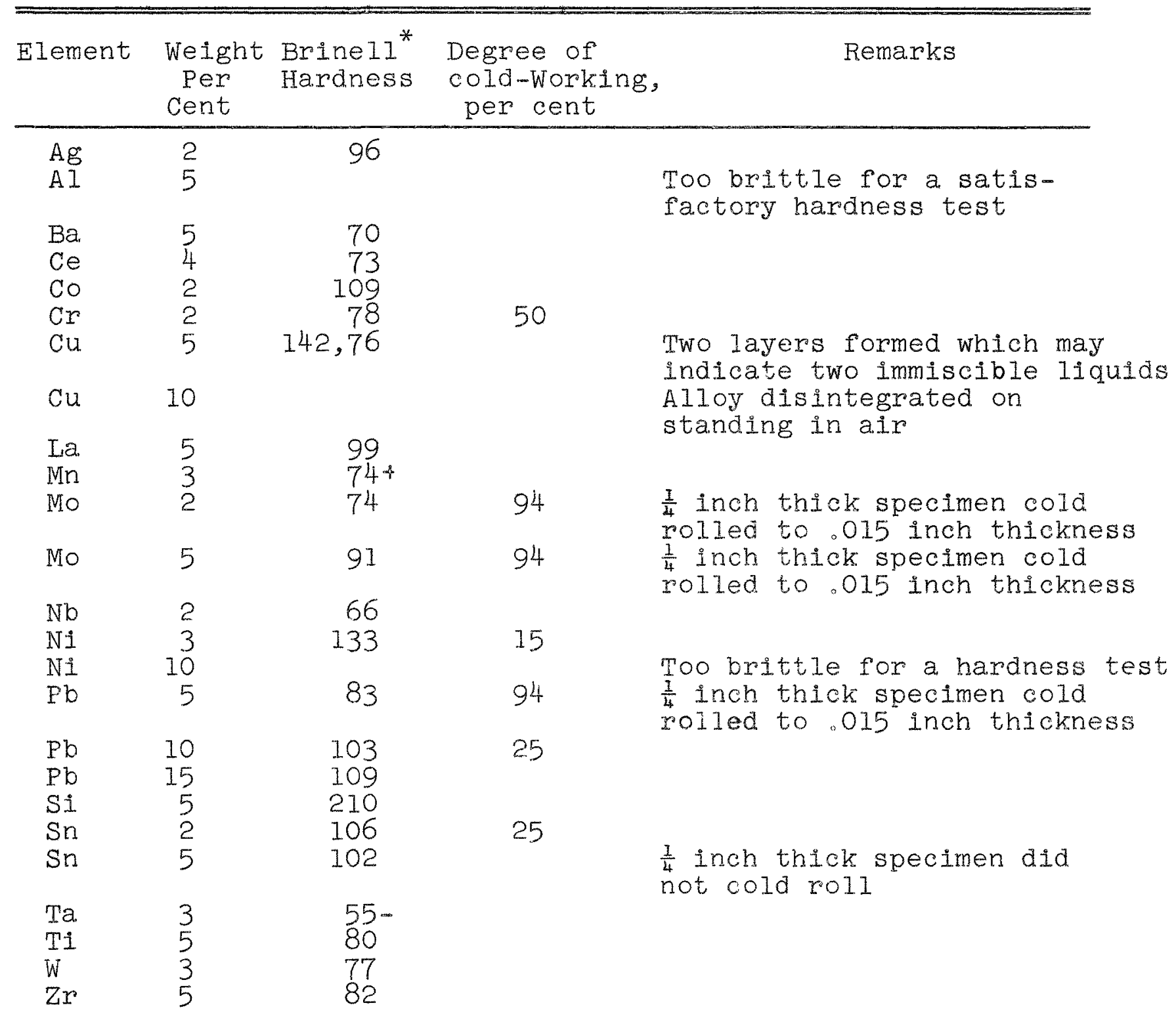

"Hardness values were determined on the Rockwell A, B or E scales and converited to Brinell hardness readings for comparison. The hardness of the unalloyed thorium was Brinell 69 (500 Kg。 load)。 
III. MISCELLANEOUS METALLURGY

A. Uranium-Molybdenum Alloys (B.A. Rogers, G.E. Faulkner, and

Several alloys containing uranium and molybdenum were prepared in the tungsten-electrode arc furnace. Alloys containing from 15 to 25 atomic per cent molybdenum could be cold-rolled to about 75 per cent reduction in thickness without intermediate annealing; those containing 5 and 10 atomic per cent molybdenum were less ductile. However, by alternately annealing and coldrolling the 10 per cent alloy, it could be reduced also.

A satisfactory annealing procedure has been worked out in which the specimens to be annealed are placed in a clear, fused silica tube which is evacuated to less than one micron of pressure and then flushed several times with purified helium. Between each flush the tube is evacuated to less than one micron. Following the last flush the tube is evacuated and then sealed off from the rest of the system by closing a stop cock. The tube and specimens are heated to $800^{\circ} \mathrm{C}$, held for 10 minutes and then cooled rapidly by plunging the tube into water, or by wrapping it with wet cloths. This appears to be a satisfactory method of retaining the gamma phase of uranium in the 10 per cent molybdenum alloy. The hardness of the annealed specimens is about Rockwell A 51. After annealing, the alloys may be cold-worked safely until their hardness reaches Rockwell A 64 when further annealing is necessary to prevent cracking.

B. Uranium-Zirconium Alloys (D。Peterson)。

A series of uranium-zirconium alloys were prepared by arc melting Bureau of Mines Sponge zirconium with uranium metal. These alloys were studied by thermal analysis and by microscopic examination. The results obtained on these alloys agreed with those found on alloys prepared by other methods.

The experimental work on this alloy system was discontinued and the results of the investigation will be distributed as a project report. 
C. Molybdenum-Rhenium Alloys (B.A. Rogers and H.W. Maynor)。

During the early part of the period covered in this report work continued on the investigation of the molybdenum-rhenium a.1loy system. This investigation was originally started in order to find which alloys might be suitable for use as thermocouple elements. Later in the period work was temporarily halted on this project in favor of more urgent work. However, it is planned to resume the study as soon as time and personnel again become available.

To the present time, wires containing 5, 10, 25 and 35 per cent rhenium have been made. Two alloys, containing 15 and 50 per cent rhenium respectively have been compacted but need to be sintered and swaged into wire form. It appears that rhenium is soluble up to 35 per cent by weight in molybdenum. The specific resistance of the 25 per cent rhenium alloy has been determined to be within the range from 73.9 to 83.45 microhm-cm.

D. Titanium-Vanadium Alloys (R。M.Powers)。

When a study of this system was begun, no commercial source of high purity vanadium was avallable, although Kroll process titanium sponge of good quality could be obtalned. Even the vanadium from the bomb reduction of $\mathrm{V}_{2} \mathrm{O}_{5}$ by calcium was not of remarkable ductility or uniformity.

While a number of methods are possible for the preparation of Ti-V alloys, it was decided in view of the high degree of reactivity of these metals with both crucible materials and gases to employ powder metallurgical methods, sintering the compacts under vacuum. It was felt that a convenient source of pure powdered Ti and $V$ could be obtained from an analogous process to that used for preparation of $Z r^{\circ}$ powder, that is, from the electrolysis of the fused salt baths. Also, the apparatus used for carrying out Zr electrolysis was available. Considerable time was spent in investigating the possibility of preparing powders of Ti and $V$ by electrolytic means.

Since the beginning of this work, however, Jo Long has developed a process for rather conststently producing 50 gram lots of relatively pure $V$ by the calcium reduction of $V_{5} O_{5}$ using a sulfur booster. Studies have recentiy begun on the phase system $T i-V$ using vanadium produced in this manner together with 
sponge titanium that has been "de-gunked" by heating at $1050^{\circ} \mathrm{C}$ under a. $O 1$ micron vacuum. The metals are are melted together several times in a water-cooled copper crucible under an argon atmosphere, to produce homogeneous biscuits.

A number of small scale tests was made to determine conditions under which vanadium could be deposited electrolytically. For these test runs the baths varied in composition. Salt mixtures of $\mathrm{K}_{2} \mathrm{VF}_{5}$ and $3 \mathrm{NaCl}$, or $\mathrm{K}_{2} V F_{5}$ and $3 \mathrm{KCl}$, or $\mathrm{K}_{2} V F_{5}$ and 1.5 NaCl and $1.5 \mathrm{KCl}$ were used in most cases. The advantage of KCI in increasing the water solubility of the cathode deposit salt matrix, was offset by the initialiy higher melting point of the salt bath i。e. $735^{\circ} \mathrm{C}$ instead of $680^{\circ} \mathrm{C}$. The vanadium salt is prepared by first reducing the air dried pentoxide to the trioxide under hydrogen at $800^{\circ} \mathrm{C}$. The oxide in Fluorethene beakers is then dissolved in 48\% hydrofluoric acid, and the green solution decanted into another fluorethene beaker where apple green $\mathrm{K}_{2} \mathrm{VF}_{5}{ }^{\circ} \mathrm{H}_{2} \mathrm{O}$ is dropped out of solution by addition of $\mathrm{KF} \cdot 2 \mathrm{H}_{2} \mathrm{O}$ crystals.

In order to prepare usable powdered metal by electrolysis, It is necessary to foirst dehydrate the above salt under HF at $350^{\circ} \mathrm{C}$, then to cool in a stream of argon. The subsequent operations, weighing, mixing with the proper amounts of NaCl or KCl and preheating, should be carroied out in as anhydrous a manner as possible since the presence of oxygen in the bath in any of its forms, whether from the a.ir directly or resulting from hydrolysis of the fluovanadate, appears to have a deleterious effect upon the character of the powdered metal deposit. Some interaction occurs at the graphite cathode. Because of this, the electrolyses were not continued for long enough times to produce sizeable amounts of product. The fines were found to be in considerable excess of the usable intermediate fraction, indicating too low a current density ( $-375 \mathrm{amps} / \mathrm{dm}^{2}$ at $800^{\circ} \mathrm{C}$ ) was employed to effect adequate sintering. To correct this it wll1 be necessary to use a water-cooled nickel cathode.

An analogous bath to that employed for Zr electrolysis was used to prepare titanium powder. The bath was composed of $\mathrm{K}_{2} \mathrm{TiF}_{6}$ and $4 \mathrm{NaCl}$ or $4 \mathrm{KCl}$. The Fluotitanate was prepared by dissolving titanium dioxide in 48\% HF, then treating the decanted supernate with $\mathrm{KF} \cdot 2 \mathrm{H}_{2} \mathrm{O}$ to precipitate pure white $\mathrm{K}_{2} \mathrm{TiF}_{6} \mathrm{H}_{2} \mathrm{O}$. Average yields of $95 \%$ theoretical were obtained in preparation of approximately 45\# of this salt. In an intermediate scale run in which the charge was $900 \mathrm{~g}$. $\mathrm{K}_{2} \mathrm{TIF}, 560 \mathrm{~g}$. KCl and $438.5 \mathrm{~g}$. NaCl, the bath was electrolyzed four times. After each electrolysis, the metal salt deposit was knocked from the end of the $5 / 8$ ths inch watercooled Nickel cathode, which was then re-inserted into the bath. 
This procedure was adopted in orger to maintain a higher average current density $\left(520-840 \mathrm{amps} / \mathrm{dm}^{2}\right)$ than could be obtained by collecting a single deposit. The run was carried out at 735$755^{\circ} \mathrm{C}$. The bright, irregular metal powder ( 325 mesh) was liberated from the salt by placing the deposit, broken to pea sized lumps in a mortar, in a Waring Blendor filled with distilled water. The action of the rotating knives on the deposit, rapidIy reduced it to powder. By repeated decantation of the salt solution together with the black metal fines, till no more salt was detected in the wash water, powder of the proper size for compacting was obtained. The yield of coarse powder was $49 \%$, of fine $39 \%$ of theoretical. That this powder was not all metal was indicated when 39.6 grams of it compacted at 10 tons/in. and carefully sintered for 1 hour at $1050^{\circ} \mathrm{C}$ in a vacuum less than 22 microns at all times, lost 5 grams of a filuffy black deposit that analyzed $27.5 \% \mathrm{Ti}$. A photomicrograph of one of these compacts that had been further heated is shown in Figure 25. It had been subjected to a rapid sinter that occurred when a large current was passed through a pressed bar compact of it under vacuum, causing it to melt in two.

An attempt was made to prepare two Ti-V alloys by co-reduction. It was hoped that by starting with the oxides in the desired mol ratio, a similar ratio would be approached in the resulting alloy. In the case of the 90 mol per cent vanadium a.1loy, 147 grams of $89 \%$ black fused $\mathrm{V}_{2} \mathrm{O}_{5}$ was combined with 12.8 grams of pure air dried Tion (Eimer and Amend). To this was a.dded 300 grams of re-distilled calcium (Ames) which represented a 60 mol per cent excess, and 24 grams of pure sublimed sulfur. The charge was tamped into the dolomite 11 ner of a $2 \frac{1}{2}$ "bomb and placed in a gas fired barrel-type furnace. The charge fired after three minutes, the outside of the bomb reaching a maximum temperature of $905^{\circ} \mathrm{C}$. The yield, 53.5 grams of a. bright biscuit, was $54.8 \%$ of theoretical.

A similar charge was made up for an $80-20 \mathrm{~V}-\mathrm{Ti}$ a.110y. Less than the calculated amount of $S$ was used out of caution so that the maximum temperature reached was on $1 \mathrm{y} 835^{\circ} \mathrm{C}$ and the yield 46. $9 \%$. From a comparison of the powder patterns of the coreduced alloys and those of known $\mathrm{T} I$ and $V$ content, the present indications are that considerably less than the 10 or $20 \mathrm{~mol}$ per cent of Ti have found their way into the alloys in these two cases. 


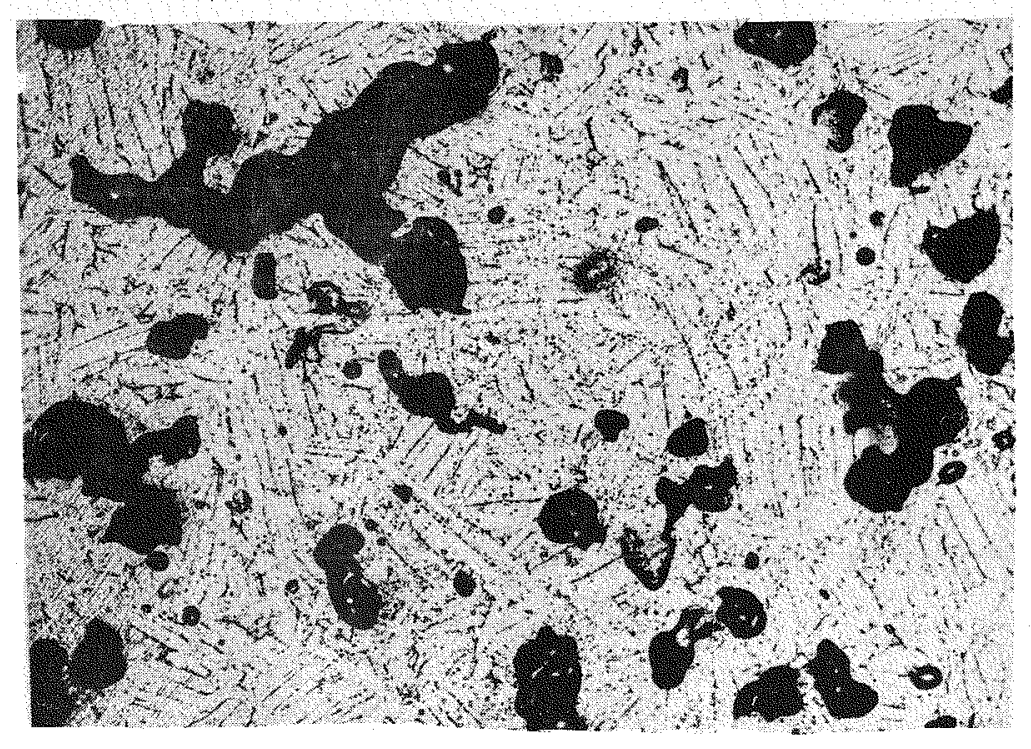

Fig. 25。 Electrolytic Titanium 250X. Powder pressed at 10 tons/in ${ }^{2}$, vacuum presintered at $1050^{\circ} \mathrm{C}$ for $1 \mathrm{hr}$. followed by vacuum melting of compact by passage of current. Area shown lies in vicinity of melted region. Etchant: Glycerol, cono. $\mathrm{HNO}_{3}, 48 \% \mathrm{HF}$ in ratio by volume of $3: 1: 1$. 
E. Vanadium Reductions ( $J$.R. Long).

Experimentation on the calcium reductions $\mathrm{V}_{2} \mathrm{O}_{5}, \mathrm{~V}_{2} \mathrm{O}_{3}, \mathrm{VF}_{3}$, and $V_{2} S_{3}$ to vanadium metal have been successful. ${ }^{2}$ For $^{2}$ these reductions, the preparations of the trioxide, trifluoride and trisulfide were carried out in this Laboratory from technical grade $\mathrm{V}_{2} \mathrm{O}_{5}$ available commercially.

Fused technical grade $\mathrm{V}_{2} \mathrm{O}_{5}$ was successfully reduced to metal. However, sulfur was the only booster which would give an appreciable yield $(50-70 \%)$ on the small scale reductions employed. A typical charge consisted of fused tech vanadium pentoxide $\left(89 \% \mathrm{~V}_{2} \mathrm{O}_{5}\right)-180 \mathrm{~g}$; $\mathrm{Ca}-333 \mathrm{~g}$. $\mathrm{S}-20 \mathrm{~g}$. Hardness values (Vickers) ranged from 150 to 190 on the biscuit metal. An iodine booster in varying proportions never gave over a $20 \%$ yield on this scale. potassium chlorate gave better yields, up to $45 \%$, but the Vickers hardness values ran over 300. Further reductions were made using a sulfur booster in an attempt to increase the yield and lower the hardness value of the metal, but were without success,

Thermodynamic calculations indicate the feasibility of the reduction of $\mathrm{V}_{2} \mathrm{O}_{3}$ to a vanadium biscuit, provided enough heat can be added to melt the metal. A sulfur booster was decided on using a weight ratio of sulfur to tech. $\mathrm{V}_{2} \mathrm{O}_{3}$ of 0.3 to I, whereas an iodine booster would require a prohibitive weight of ten times as much iodine. A typical charge using $60 \%$ excess $\mathrm{Ca}$ is made up of tech. $\mathrm{V}_{2} \mathrm{O}_{3} 150 \mathrm{~g}$, $\mathrm{Ca} 293 \mathrm{~g}$, and $\mathrm{S} 50 \mathrm{~g}$. The tech. $\mathrm{V}_{2} \mathrm{O}_{3}$ was xeduced from air-dried technical grade vanadium pentoxide $\left(81 \% \mathrm{~V}_{2} \mathrm{O}_{5}\right)$ by hydrogen at a temperature of $650^{\circ} \mathrm{C}$ for a period of 8 hours. The results of the calcium reductions to the metal were very encouraging. Yields eventually reached $80 \%$ with Vickers hardness values ranging from 140 to 160. A small portion of one of these biscuits was successfully cold rolled from a thickness of $1 / 4$ inch to 0.011 inch.

Technical grade $\mathrm{VF}_{3}$ had been previously prepared from the tech, $\mathrm{V}_{2} \mathrm{O}_{3}$ described above, by the reaction with anhydrous HF atmosphere. Reduction employing the use of a sulfur booster and $60 \%$ excess Ca produced a good biscult of metal with yields around 85\%。Usual charges employed tech。VF3 $216 \mathrm{~g}$, $\mathrm{Ca} 206 \mathrm{~g}$ 。, $\mathrm{S} 7 \mathrm{~g}$. Hardness values of this metal ( 175 - 225 vickers) ranged considerably higher than those reduced from the oxide.

Since vanadium metal could be reduced from tech. $\mathrm{V}_{2} \mathrm{O}_{3}$ using a large quantity of sulfur as booster, the possibility of obtaining the metal from a vanadium sulfide seemed feasible. The 
heat of reaction of the sulfide with calcium was calculated (using certain assumptions) and was found to approach that of the fluoride with calcium.

The simplest method of preparing a technical grade vanadium sulfide appeared to be the solid-gas reaction of $\mathrm{H}_{2} \mathrm{~S}$ on tech. $\mathrm{V}_{2} \mathrm{O}_{3}$. About 90\% conversion to $\mathrm{V}_{2} \mathrm{~S}_{3}$ was obtained at a reaction temperature of $850^{\circ} \mathrm{C}$ for a period of 24 hours. Reduction to the metal could be obtained without a booster but $5 \mathrm{~g}$. of sulfur to $198 \mathrm{~g}$. of tech. $\mathrm{V}_{2} \mathrm{~S}_{3}$ was necessary with $198 \mathrm{~g}$. of $\mathrm{Ca}$ ( $60 \%$ excess) to produce a satisfactory biscuit. The best yield was $78 \%$ with a Vickers hardness number of 175 . However, a.II of the biscuits were pitted and possessed a greyish color. The preparation of $\mathrm{V}_{2} \mathrm{~S}_{2}$ by the action of $\mathrm{S}$ on $\mathrm{V}_{2} \mathrm{O}_{5}$ in a $\mathrm{CO}_{2}$ atmosphere at $400^{\circ} \mathrm{C}$ as described by Gerasimov and Chunikhina, was not confirmed. The product obtained was $\mathrm{V}_{2} \mathrm{O}_{3}$ as stated by Berzelius and by Ditte.

A comparison of the various reduction processes employing present data on technical grade materials indicates that the softest metal was obtained from $\mathrm{V}_{2} \mathrm{O}_{3}$ while the best yields were obtained from VF3. The ratios of calcium metal employed to vanadium metal produced ran around 2.5 for the fluoride reductions as compared to the values of 3.0 for the sulfide reductions and 4.0 for the oxide reductions. It is probable, however, that the labor costs involved in the preparation of the sulfide and. fluoride would offset the cost of the larger amounts of calcium employed in the oxide reductions. 


\section{EQUIPMENT AND MISCELLANEOUS ITEMS}

A. Tungsten Electrode Arc Furnace (B.A. Rogers and G。E。Faulkner)。

The tungsten electrode arc furnace, previously described in ISC-128, has been modified to produce a better vacuum, to allow the operator better visibility for small melts, and to introduce a method for gettering the atmosphere to remove traces of contaminating gases. A brass sylphon tube replaces the rubber sleeve surrounding the electrode, the vacuum lines have been shortened and shorter lengths of rubber vacuum hose are used. A spacer, containing two sight glasses at 180 degrees, separates the head and the crucible. This spacer, used with a large diameter, shortened crucible, allows the operator full visibility over the bottom of the crucible. There are two shallow depressions in the crucible bottom. The smaller one contains a charge of zirconium, usually about 25 grams, which is melted first to getter the a.tmosphere. The larger depression holds the main charge which is melted into the form of a flat button. After becoming solid, the button may be flipped over with the electrode, when the power is off, and remelted to obtain better homogeneity. Generally the getter is harder by 6 or 7 points on the Rockwell A scale than the ingot, which is some indication of the getter's scavenging power.

Arc furnace experiments in which a $\frac{1}{4} "$ diameter tungsten tip was substituted for the $\frac{1}{2}$ " diameter tip have shown that melting of 100 gram charges is obtained with lower currents, 200 to 300 amperes, and that the arc is more easily controlled.

During the past six months the are furnace has been in daily use for alloy preparation. Some of these alloys include binary ones of zirconium with aluminum, copper, germanium, niobium, tin, tantaIum and uranium. Alloys of uranium and molybdenum, zirconium-tin and niobium and several binary alloys of thorium with various percentages of other metals have been prepared and are discussed elsewhere in this report.

B. Consumable Electrodes (B.A. Rogers and W.N. Miner)。

An unsuccessful attempt was made to form consumable electrodes of zirconium by hot forging for use in an $A C$ arc melting furnace. The work was attempted by a commercial forging shop but in each 
trial the steel jackets cracked after repeated hammering. There is no doubt that with further study electrodes may be made in this manner or in a similar way such as by extrusion. However, this project has been postponed in favor of more urgent work and no immediate further investigation is contemplated.

C. Tungsten Crucibles (B.A. Rogers and W.N. Miner)。

Because tungsten crucibles of a size needed in certain chemical engineering work were unavailable commerclally, a process was worked out for making them in the metallurgical laboratory。 Type 427 tungsten powder, obtained from the Fansteel Metaliurgical Corporation, was mixed with a small amount of Carbowax, as a binder, and pressed at about 60,000 psi into a fragile crucible. The cruolible was about $1 \frac{1}{2}$ inches high, 1 inch inside diameter and had $\frac{1}{4}$ inch thick walls with a $\frac{1}{4}$ inch thick rounded bottom. The green crucible was heated slowly in an electrical resistance furnace, under a vacuum of from 1 to 10 microns, to $800^{\circ} \mathrm{C}$ where it was held for three hours. Following this treatment the furnace and crucible were allowed to cool to room temperature. The crucible was then sintered in a graphite crucible by induction heating under a vacuum of from 15 to 40 microns to a temperature of from 2000 to $2100^{\circ} \mathrm{C}$ for 30 minutes. The resulting product was a hard, dense, bright crucible which has had considerable use and seems to be performing satisfactorily.

D. Vacuum Fusion Equipment (B.A.Rogers and A.J.Carison)。

Equipment has been designed and is now under construction that will enable the quantitative determination of several gases by the vacuum fusion method. The main objective in setting up this equipment, however, is the determination of oxygen in metals.

E. Dilatometer (B,A。Rogers and R。E.Kleint)。

A dilatometer which will automatically record dimensional changes is being constructed and will be used in thermal studies on alloys. The apparatus is based on the use of Iinear differential transformers. 
F。 Helium Densitometer (R。M. Powers).

A helium densitometer (Figure 26) was built to enable a rapid estimation of density to be made of metal powders and alloys of the Ti-V system. The He displacement volume of a substance is measured in this apparatus. A modification included a blank volume in parallel with the system to compensate for any change in surrounding pressure or temperature during a run.

After calibrating weights used with the triple beam balance the apparatus was checked against pure powdered zinc (20 mesh) giving a value of $7.15 \& .07 \mathrm{max}$. dev。g/cc in contrast to the Metals Handbook value of $7.13 \mathrm{~g} / \mathrm{cc}$.

The usual type of helium densitometer has been modified by the inclusion of a parallel blank volume above stopcock 2 (Figure 26) to compensate for any change in pressure or temperature in the surroundings during a measurement. With the powder placed in the sample holder, and mercury levels held above stopcocks 5 and 6. the entire system above stopcock 8 is evacuated for ten minutes or so During this time, the weight of mercury in the weighing bottie on the right is determined on a balance. The bulb containing the sample is then isolated from the rest of the system by closing stopcock 4 and helium is admitted to the entire system including the blank volume at an arbitrary pressure (usually near atmospheric). Stopcocks 2 and 3 are then closed. By opening stopcock 4 thus introducing additional volume to the system, the pressure drops It may be restored by opening 6 and forcing mercury up into the system by compressed air. Equalization of pressure is indicated by bringing mercury levels in the measuring and blank systems to the same height. The volume of mercury added in this manner is equal to the free volume of the sample bulb. It is determined from the change in weight of the mercury in the weighing bottle and its temperature. From the difference in volume of the sample bulb when empty and when full of a weighed powder sample, the powder volume, and consequently its density may be obtained. A run requires approximately 20 minutes. The method is especially useful for determination of powder densities where the pycnometric method with incomplete wetting of the powder by the fluid would lead to too low densities. 


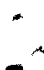

$-$

i

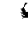

$+$

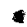

$*$

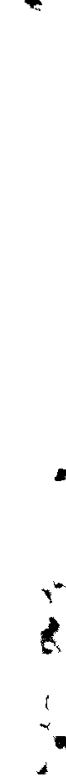

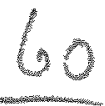

Fig。26

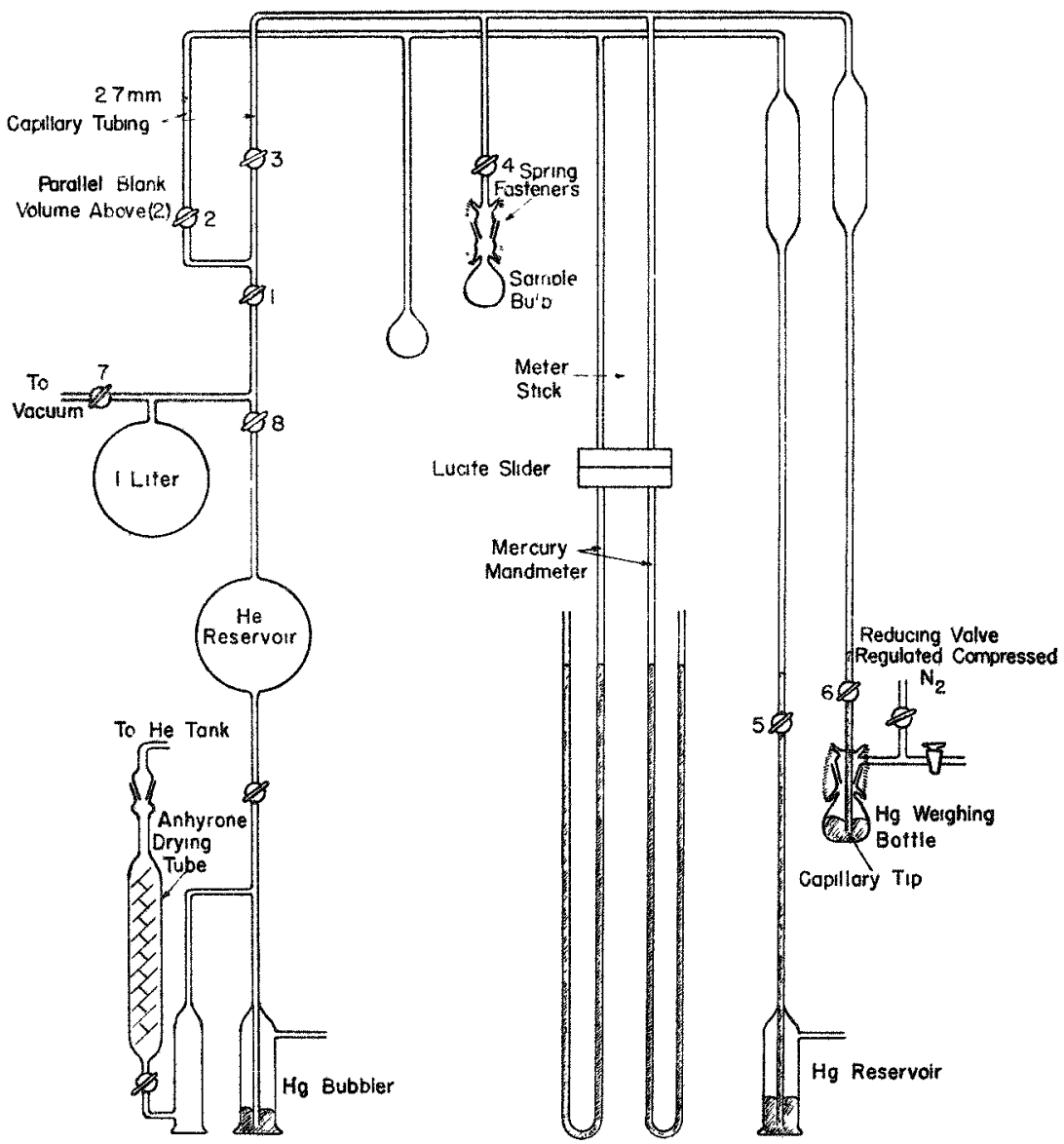

HELIUM DENSITOMETER 
G. Hafnium Oxide Crucibles (B.A. Rogers and E.S. Hodge)。

Hafnium oxide crucibles containing 90 per cent hafnium oxide and 10 per cent zirconium oxide have been prepared in the laboratory. The hafnium oxide powder was jolt-packed and fired succesivively in graphite at $1750^{\circ} \mathrm{C}$, in magnesium oxide at $1850^{\circ} \mathrm{C}$ and in thorium oxide at $2100^{\circ} \mathrm{C}$. The sintered crucible resulting from this procedure was hard and dense. In one test, a charge of crystal bar zirconium was melted in the crucible which showed. little evidence of attack. Crucibles containing 98 and 99.6 per cent hafnium oxide will be made in the near future.

H. Elutriation Grinder (R.M. Powers).

The elutriation grinder pictured in Figure 27 has been used successfully to liberate powdered metal from salt in electrolytic deposits. The stainless steel Waring Blendor shown in the figure is the heart of the apparatus. It is fitted with a screw-on cap which is topped with a cone and overflow launder, an inlet tube also being an integral part of this cap.

In operation, lumps of the cathode deposit are placed in the water filled Blendor and the cap screwed on. When the Blendor is turned on, the combined action of the blades and accelerated solution of the salt, rapidiy breaks up the deposit. Water flows into the apparatus from the inlet tube while salt solution together with unusable fines run out the overflow launder and are collected in a beaker. Eddying that occurred in the grinder was largely prevented by placing $a$. 10 mesh screen at the base of the cone and a baffle half way across it. By varying flow rates, the particle size of the residual metal may be controlled.

Less water is used when the Blendor is operated batch wise, minus its cap, Decantation of the salt and fines, and addition of more distilled water follow each break-up operation until no salt can be detected in the water. 


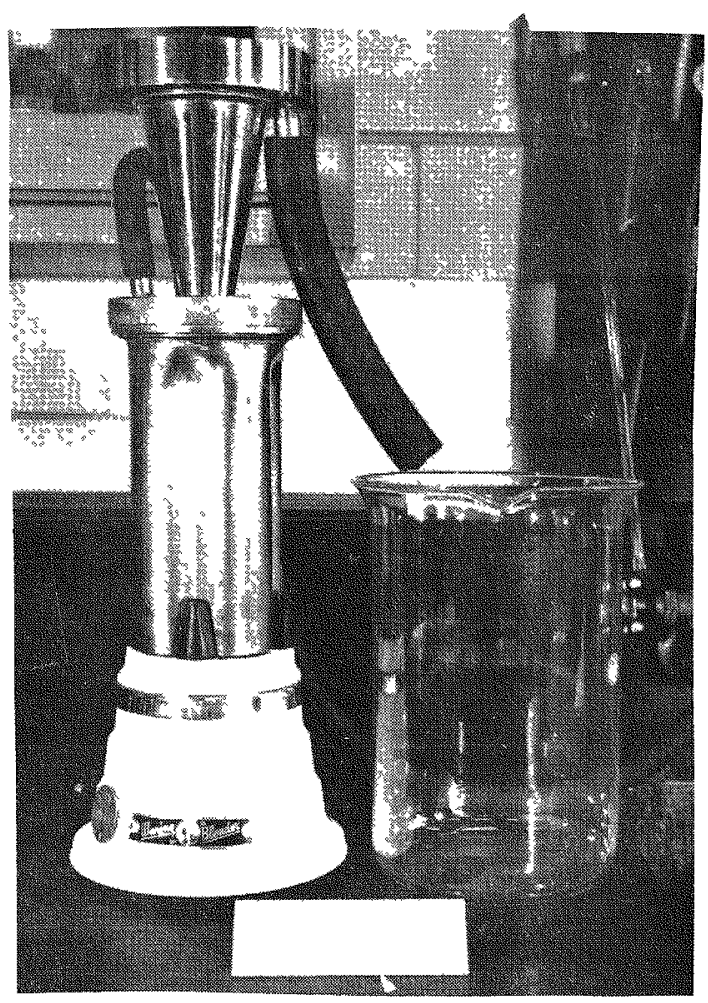

Figo 27. Elutriation Grinder 